\title{
The Social Costs of Second-Best Policies: Evidence from Agricultural GHG Mitigation
}

\begin{abstract}
This paper investigates the social costs of second-best agricultural greenhouse gas (GHG) mitigation policies. Adjustments along the land use and input intensity margins are represented within a regionalized optimization model of California crop production calibrated to economic and agronomic information. Second-best policies relying on spatially aggregated GHG emission factors lead to small abatement efficiency losses, while policies targeting a single GHG lead to moderate losses. In contrast, policies targeting a single input entail large abatement efficiency losses, which nonetheless can be reduced by combining instruments.
\end{abstract}

JEL codes: Q50, Q10, C61

Keywords: greenhouse gases, climate policy, second best, abatement efficiency

Policymakers worldwide have recognized climate change as one of the greatest challenges of our time and agreed that substantial reductions in greenhouse gas (GHG) emissions are in order (UNFCCC, 2010, 2015). This political will has led to the emergence of international agreements such as the Kyoto Protocol and the adoption of national and subnational climate policies (Burtraw, 2013). A common feature of these policies is that they set goals to decrease GHG emissions relative to business as usual by some future date. ${ }^{1}$

\footnotetext{
${ }^{1}$ Besides California, the focus of the present paper, jurisdictions having initiated efforts to
} 
The burning of fossil fuels represents a large share of global GHG emissions, and regional climate policies have often prioritized emission reductions from the energy generation sector and from energy-intensive industries. Because GHG emissions from these sectors are traceable to a well-identified source, marketbased policies directly addressing GHG emissions such as cap-and-trade are generally thought to be economically desirable and have been implemented in several jurisdictions (Bushnell et al., 2013, 2014). ${ }^{2}$

In the U.S., the agricultural sector accounts for about $9 \%$ of total GHG emissions, mainly in the form of nitrous oxide $\left(\mathrm{N}_{2} \mathrm{O}\right)$ and methane $\left(\mathrm{CH}_{4}\right){ }^{3}$ Agricultural soils can also store carbon, thereby contributing negatively to GHG emissions. A growing body of literature suggests that, owing to its GHG mitigation potential, the agricultural sector could be part of a multi-facet GHG mitigation strategy (McCarl and Schneider, 2001; Pautsch et al., 2001; Antle et al., 2007a).

In contrast to energy-based sectors, agriculture emits GHGs from a very large number of heterogenous sources at which emissions measurement is not economically feasible, making a first-best policy difficult to implement in the foreseeable future. Despite this difficulty, the contribution of the agricultural sector to GHG mitigation efforts has remained on the climate policy agenda of national and sub-

reduce GHG emissions include the European Union, who launched its Emissions Trading System in 2005 with an objective to reduce emissions from targeted sectors by $21 \%$ by 2020 relative to 2005, and nine states of the Northeastern U.S. participating in the Regional Greenhouse Gas Initiative (RGGI), a cap-and-trade system implemented in 2009 to reduce power sector emissions by $10 \%$ by 2018 relative to 2009 . In November 2014, the world's largest two emitters, China and the U.S., jointly announced commitments to reduce GHG emissions. The U.S. set a new target to cut net GHG emissions $26-28 \%$ below 2005 levels by 2025 while China announced targets to peak emissions of carbon dioxide around 2030. The recent Paris Agreement states in its Article 2 that "Parties aim to reach global peaking of GHG emissions as soon as possible."

${ }^{2}$ A notable exception is Fowlie et al. (2016) who find that in the U.S. Portland cement industry, domestic market power together with emissions leakage would make carbon pricing welfare-reducing.

${ }^{3}$ Not counting soil carbon sequestration, over half of the GHG emissions from U.S. agriculture come from $\mathrm{N}_{2} \mathrm{O}$ emissions due to soil management. Enteric fermentation in livestock accounts for almost one third of emissions in the form of $\mathrm{CH}_{4}$. Manure management contributes to $\mathrm{CH}_{4}$ and $\mathrm{N}_{2} \mathrm{O}$ emissions, accounting for about $12 \%$ of the total GHG emissions from the agricultural sector. Rice cultivation and the burning of crop residues also contribute small amounts of GHG in the U.S. (Environmental Protection Agency, 2015). In California, the agricultural sector accounts for $8.3 \%$ of total GHG emissions. The main contributors are manure management (32.1\%), enteric fermentation (31.1\%), and soil management (23.2\%). Energy use and rice cultivation account for most of the remainder of GHG emissions (CARB, 2014a). 
national agencies (Horowitz and Gottlieb, 2010; CARB, 2014b). ${ }^{4}$ However, in the absence of information on the abatement efficiency of realistic agricultural GHG mitigation programs, it is hard to see how these agencies could successfully include the agricultural sector in existing or planned mitigation policies.

The goal of the present paper is to investigate the social costs of secondbest policies aimed at incentivizing agricultural GHG emission reductions and to assess the role that the agricultural sector could play in GHG mitigation. We go beyond existing studies on the mitigation potential of agriculture by quantifying the abatement efficiency costs associated with a suite of second-best instruments that are thought to entail lower implementation costs than the first best.

We address the abatement efficiency of second-best agricultural GHG mitigation policies in the empirical context of field crop agriculture in California. California is a relevant setting to investigate this issue for at least three reasons. First, although its agricultural acreage is relatively modest compared to that of the entire U.S., California leads the nation in terms of value of agricultural output, making the tradeoff between agricultural production and GHG mitigation particularly salient. Second, its agriculture is highly diverse and is therefore well-suited to investigating the impact of source heterogeneity on abatement efficiency. Finally, California has the most advanced GHG mitigation policy in the U.S., including recent plans to reduce emissions from the agricultural sector. In 2006, California approved the Global Warming Solutions Act, often referred to as AB 32, a pioneering law that aims to reduce the state's emissions to 1990 levels by 2020 (Assembly Bill 32, Nuñez, Chapter 488, Statutes of 2006). In 2014, the California Air Resources Board (CARB), charged with the rule-making process for AB 32, approved in its First Update to the AB 32 Scoping Plan the objective of establishing GHG emission reduction planning targets for agriculture for the period leading to 2050 (CARB, 2014b, pg. 61). ${ }^{5}$ Our paper therefore contributes

\footnotetext{
${ }^{4}$ In 2010, the U.S. Department of Agriculture launched a research program titled "Economics of Markets for Agricultural Greenhouse Gases" focusing on the economics of GHG reductions from U.S. agriculture. In California, Appendix C of the First Update to the AB 32 Scoping Plan relative to the agricultural sector recommends to "establish stable funding to provide short and long-term research [...] opportunities to determine [...] the cost effective and environmentally beneficial practices that reduce GHG emissions."

${ }^{5}$ CARB has also approved the Compliance Offset Protocol U.S. Forest Projects for crediting carbon sequestered on forest land (protocols/usforestprojects) and the Compliance Offset Pro-
} 
to a relevant policy debate.

To answer our empirical question, we build a regionalized optimization model of California field crop production calibrated to economic and agronomic information. The level of disaggregation of the model captures part of the spatial heterogeneity in soil and climatic conditions as well as regional differences in cropping patterns and resource constraints. The model allows for crop substitution and continuous changes in fertilizer, irrigation, and tillage intensities. We use biophysical information obtained from a biogeochemical model to calibrate crop yield responses to input intensities and to derive so-called emission factors, that is, GHG emission rates per hectare conditional on crop choice and input intensities. We validate our calibrated model by predicting crop acreage and output under out-of-sample economic conditions and comparing the results to observed patterns. Despite being relatively stylized, our model performs reasonably well, which suggests that it captures relevant tradeoffs at the regional scale.

We begin our analysis by simulating California's marginal abatement cost curve under the first-best GHG emission reduction policy. One way to conceptualize the first-best policy is to imagine that the regulating agency offers payments to farmers in exchange for GHG emission reductions relative to a baseline. The agency must be able to either verify actual emissions (which would require measurement) or, more realistically, infer them by observing management practices. The latter inference is likely to be based on knowledge gained from biophysical models - such as the one used in this study - about the relationship between various agricultural practices and GHG emissions, i.e., the emission generation process. ${ }^{6}$ In our cropping system, GHG emissions arise from several adjustment margins and the emission process is location-specific due to differences in soils and climate. As such, a first-best incentive scheme would necessarily entail a complex schedule of emission factors linking agricultural practices to emissions. Such a complex schedule may be costly to generate; the policy may also be costly to implement and politically difficult to enforce, as it would entail the differentiated

tocol Livestock Projects for crediting GHG emission reductions associated with the installation of biogas control systems for manure management on dairy cattle and swine farms (protocols/livestock).

${ }^{6} \mathrm{CARB}$ is currently contemplating the use of model-based GHG emission factors for $\mathrm{N}_{2} \mathrm{O}$ and $\mathrm{CH}_{4}$ for the purpose of crediting carbon offsets from flooded rice fields (CARB, 2014c). 
treatment of farms that differ in terms of biophysical characteristics.

The second part of our analysis thus investigates the abatement efficiency losses that would arise under four types of second-best policies aimed at reducing these costs: (i) policies relying on spatially uniform emission factors, ${ }^{7}$ (ii) policies regulating a single GHG, (iii) policies controlling a single agricultural input irrespective of its use, and (iv) policies controlling a combination of inputs. Each of these policies entails a reduced informational burden, and some may also entail a reduced enforcement burden, relative to the first-best policy.

Our simulations show that field crop agriculture in California could abate 1.03 million metric tonnes of $\mathrm{CO}_{2}$ equivalent $\left(\mathrm{MtCO}_{2} \mathrm{e}\right)$ per year under a firstbest policy at a carbon price of $\$ 20 / \mathrm{tCO}_{2} \mathrm{e}$, the price anticipated by CARB in 2020 (CARB, 2010c). ${ }^{8}$ This abatement figure represents $30 \%$ of baseline GHG emissions from our modeled cropping system and $12 \%$ of CARB's estimated GHG emissions from agricultural soil management in the entire state, suggesting that field crop agriculture could potentially contribute to the state's emission reduction targets as part of its portfolio of abatement measures (CARB, 2010b).

Our analysis further reveals that second-best policies that rely on spatially uniform emission factors lead to small abatement efficiency losses relative to the first-best policy. For instance, at a GHG abatement target of $1 \mathrm{MtCO}_{2} \mathrm{e}$ per year, social opportunity costs increase by only $8 \%$ when using statewide emission factors as opposed to regional ones. This result suggests that model-based quantification of GHG emissions from fields need not be implemented at a highly disaggregated scale for policy purposes.

Second-best policies targeting single GHGs like $\mathrm{N}_{2} \mathrm{O}$ or $\mathrm{CO}_{2}$ lead to moderate efficiency losses relative to the first best. For instance, the social cost of a policy targeting $\mathrm{N}_{2} \mathrm{O}$ (resp., $\mathrm{CO}_{2}$ ) reduction is $24 \%$ (resp., 37\%) higher than that of the first-best policy at an abatement target of $1 \mathrm{MtCO}_{2}$ e per year. Finally, policies directly controlling agricultural inputs, although arguably much easier to imple-

\footnotetext{
${ }^{7}$ Spatially uniform emission factors capture the average relationship between agricultural practices and GHG emissions at a broad regional level, as opposed to finer-scale emission factors that reflect spatial heterogeneity in the GHG emission generation process.

${ }^{8}$ Burtraw et al. (2012) report an allowance price forecast of about $\$ 37 / \mathrm{tCO}_{2} \mathrm{e}$ in 2020 . The U.S. EPA estimates that, under a congressional cap-and-trade proposal, allowance prices would reach $\$ 13-59 / \mathrm{tCO}_{2} \mathrm{e}$ in 2020 (Horowitz and Gottlieb, 2010).
} 
ment, are found to entail very large abatement efficiency losses. Mixed policies that simultaneously control two inputs partially mitigate such losses. Specifically, a combination of nitrogen $(\mathrm{N})$ and tillage taxes is predicted to achieve $55 \%$ of the economic abatement potential at a social price of $\$ 20 / \mathrm{tCO}_{2} \mathrm{e}$, compared to $45 \%$ for a tillage tax and $15 \%$ for a $\mathrm{N}$ tax.

Whether second-best policies represent a viable alternative to the first best ultimately depends on their implementation costs. At the end of this paper, we therefore offer a stylized analysis of GHG mitigation policies' implementation costs. Except for the single input incentives, the second-best policies considered here generally appear justifiable from a welfare perspective. While the use of spatially uniform emission factors seems warranted, policies focussing on one GHG in isolation or ignoring crop type are clearly dominated by a policy incentivizing all margins and all GHGs.

This paper contributes to the literature on GHG mitigation from the agricultural, forestry, and land use sector by addressing the abatement inefficiencies of second-best policy instruments, an area that remains under-explored despite its policy relevance. Some studies such as McCarl and Schneider (2001) or Antle et al. (2007a) have derived GHG abatement supply curves in first-best settings, while many others have relied on cost measures that do not align with marginal social costs, often average or marginal subsidy expenditures (Stavins, 1999; Plantinga et al., 1999; Newell and Stavins, 2000; Pautsch et al., 2001; Lubowski et al., 2006; Choi and Sohngen, 2010). ${ }^{9}$ Here we systematically compute abatement efficiency losses in terms of deadweight losses, the common measure of economic inefficiency.

We also contribute to a programming-based literature on agri-environmental policy analysis, a recent review of which is provided by Mérel and Howitt (2014). Finally, our paper relates to a rich theoretical and empirical literature on the regulation of pollutants under imperfect monitoring. A substantial part of this literature has dealt with policies aimed at reducing local air pollution caused by motor vehicles through gasoline and vehicle taxes (Innes, 1996; Fullerton and West, 2002; Fullerton and Gan, 2005), driving restrictions (Davis, 2008), or gaso-

\footnotetext{
${ }^{9}$ Subsidy expenditures reflect costs to the regulating agency, which may matter in their own right; however, they often overstate the social cost of the policy, because part of the subsidy represents an income transfer to the regulated sector (Garnache and Mérel, 2016).
} 
line content regulations (Auffhammer and Kellogg, 2011). The common feature between motor vehicles and agricultural GHG sources is that the externality cannot be easily measured at the source.

The remainder of the paper proceeds as follows. Section 1 places our contribution within the context of the existing literature. Section 2 formalizes our secondbest policy framework and defines our measure of abatement inefficiency. Section 3 describes the structure of our economic optimization model, the data sources used to calibrate it, and the results of a validation test. Section 4 discusses GHG abatement under the first-best policy. Section 5 presents the marginal abatement cost curves of second-best policies and discusses the role of policy design on abatement efficiency. Section 6 investigates the implementation costs of these policies. Section 7 concludes. An Appendix provides additional details on our calibration procedure as well as a range of robustness checks.

\section{Relationship to previous work}

Here we discuss the contributions of our paper to the literature on agricultural GHG mitigation and to the programming-based literature on agricultural production modeling.

The proper incentivization of GHG emission reductions by the agricultural sector is fraught with many challenges. First, GHG emissions from fields or animals are costly or impractical to monitor, making reliance on simulated conditional emission factors, as opposed to direct emissions measurement, necessary for policy implementation. Emission factors depend on local biophysical conditions and observable practices such as crop choice and crop management and they can be used in lieu of actual measurements to provide incentives to agents (Kling, 2011). Second, the emission generation process typically involves multiple margins of adjustment, perhaps contributing to emissions in a nonlinear fashion. This feature renders the derivation of conditional emission factors complex and prone to error. Third, agricultural GHGs are emitted by many sources having their own production costs and emission generation process. Due to this heterogeneity, incentive schemes might appear inequitable or discriminatory when they reward or penalize farmers differently for the same practice. 
One option to make a GHG incentive program workable is to rely on spatially aggregated conditional emission factors instead of field- or farm-level ones. First, the informational burden associated with understanding the emissions process can be reduced by modeling emissions at a broad scale. Implementation is also eased as the payment or penalty schedules do not need to be tailored to varying local conditions. Finally, programs that reward practices based on spatially aggregated emission factors may be politically attractive since farmers with similar observable practices receive identical payments. This paper is the first to formally derive restricted social marginal cost curves reflecting the efficiency losses associated with spatially uniform conditional emission factors. ${ }^{10}$ Our results seem consistent with previous empirical evidence by Antle et al. (2007a) that using aggregate carbon sequestration rates as opposed to county-level ones produces comparable carbon supply curves.

Because carbon sequestration is arguably easier to monitor than $\mathrm{N}_{2} \mathrm{O}$ or $\mathrm{CH}_{4}$ fluxes, some studies have focused on regulating $\mathrm{CO}_{2}$ (Pautsch et al., 2001; Antle et al., 2003; Kurkalova et al., 2004; Feng et al., 2006; Antle et al., 2007a). ${ }^{11}$ Yet, agricultural management practices affect emissions of all GHGs and the discrepancies between carbon sequestration and total emissions abated may be large. ${ }^{12}$ For instance, Antle and Ogle (2012) find that accounting for the effect of no-till practices on both carbon sequestration and $\mathrm{N}_{2} \mathrm{O}$ emissions shifts the GHG offset supply curve outward for wheat-pasture systems and inward for corn-soyhay systems in the central U.S. relative to studies that omit $\mathrm{N}_{2} \mathrm{O}$ emissions. This finding suggests that incentive schemes targeting a single GHG may entail

\footnotetext{
${ }^{10}$ Antle et al. (2007a) derive carbon sequestration supply curves from reduction in fallow and conservation tillage adoption in the central U.S. They compare supply curves obtained using county-level and average (multi-state) soil carbon rates, but they do not derive the restricted marginal social cost curve associated with the use of aggregate information. Pautsch et al. (2001) derive cost measures for carbon sequestration in Iowa under various subsidy schemes but they are interested in program costs rather than social costs. De Cara et al. (2005) derive the marginal social cost of a policy consisting of an equiproportional reduction in farm-level GHG emissions. In terms of implementation such a policy still requires knowledge of disaggregated emissions or emission factors.

${ }^{11}$ Rosas et al. (2011) and Mérel et al. (2014) study $\mathrm{N}_{2} \mathrm{O}$ emissions, De Cara et al. (2005) track $\mathrm{N}_{2} \mathrm{O}$ and $\mathrm{CH}_{4}$, and De Cara and Jayet (2000) and Schneider et al. (2007) examine all three GHGs.

${ }^{12}$ For instance, reduced tillage often enhances both carbon sequestration and $\mathrm{N}_{2} \mathrm{O}$ emissions (Six et al., 2004) while reduced N fertilizer application reduces them (Snyder et al., 2009).
} 
abatement efficiency losses, a hypothesis we explicitly investigate here.

If the regulating agency has perfect information on the emission generation process, the first-best allocation can theoretically be achieved by simultaneously incentivizing the choice of activity (extensive margin) and the choice of management practices (intensive margin). Such incentives could be implemented, for instance, through crop-specific input taxes or through an abatement action permit system such as the one described by Kling (2011), whereby each observable practice is assigned a number of points commensurate with its abatement potential, the regulating agency assigns each agent a target of points to be reached, and agents are allowed to trade points. ${ }^{13}$ Yet, regulating all inputs simultaneously and differently across uses may be politically difficult and costly to implement. ${ }^{14}$ To our knowledge, no study on GHG mitigation before this one has estimated how much second-best policies regulating inputs irrespective of their use would perform relative to the first best in terms of social cost. ${ }^{15}$ Here we investigate the abatement efficiency of policies targeting fertilizer use, water use, and tillage intensity, in isolation or in combination.

Our paper also contributes to a rich mathematical programming literature addressing GHG mitigation from the agricultural and forestry sector. Linear programming (LP) has been used extensively to estimate the GHG abatement costs of agricultural and forestry sources (De Cara and Jayet, 2000; De Cara et al., 2005; McCarl and Schneider, 2001; Schneider and McCarl, 2003; Schneider et al., 2007; Godard et al., 2008; Choi and Sohngen, 2010; Durandeau et al., 2010). Yet, LP has been criticized for producing corner solutions and not calibrating to an observed baseline (Howitt, 1995b). One solution is to introduce calibration constraints that force the model to approximate the observed allocation, but these may artificially constrain the model's response to policy shocks. Another option is to use positive mathematical programming (PMP), a nonlinear programming method widely used for agricultural and agri-environmental

\footnotetext{
${ }^{13}$ If farmers know the emission generation process, the allocation can also be decentralized through an abatement subsidy or an emissions tax.

${ }^{14}$ Because inputs are often regulated by different agencies, coordination among these agencies to determine the optimal taxation of all inputs can be difficult (Larson et al., 1996).

${ }^{15}$ Durandeau et al. (2010) estimate input tax levels required to reach given GHG abatement targets in Northern France but they do not derive attendant abatement efficiency losses.
} 
policy analysis (Heckelei et al., 2012; Mérel and Howitt, 2014). PMP relies on a positive approach wherein farmers' behavior is rationalized through the use of activity-specific shadow costs, so that their observed choices maximize profits in a reference year without the use of calibration constraints (Howitt, 1995b).

We derive our results from a state-of-the-art regionalized PMP model of crop supply for California. Crop-specific production functions of the constantelasticity-of-substitution (CES) form are calibrated to economic and agronomic information, extending the method proposed by Mérel et al. (2014) to account for the choice of tillage intensity. From an empirical standpoint, allowing for this additional adjustment margin appears critical as the literature suggests that some tillage practices could help reduce GHG emissions from crop production (Lal et al., 1998, 2003; Ogle et al., 2012; Powlson et al., 2014). Our findings are consistent with this expectation.

Our economic data come from the California Department of Water Resources (DWR), County Agricultural Commissioner Reports, and the California StateWide Agricultural Production (SWAP) model developed by Richard Howitt (Jenkins et al., 2001). ${ }^{16}$ We use the biogeochemical model DAYCENT (Del Grosso et al., 2001) to estimate crop- and region-specific yield and GHG emission responses to agricultural practices. Previous studies have relied on ecosystem process-based models to represent agricultural production possibilities, for instance EPIC (McCarl and Schneider, 2001; Pautsch et al., 2001; Kurkalova et al., 2004), CENTURY (Antle et al., 2003, 2007a), DAYCENT (Springborn et al., 2013), DNDC (Neufeldt et al., 2006), STICS and CERES (Durandeau et al., 2010), and more recently the Food and Agriculture Organization's Global Agro-Ecological Zones database (Costinot et al., 2016). One typical issue facing modelers when using information generated by biophysical models is that it almost always fails to explain actual production choices, likely because the entire set of constraints and opportunities facing farmers cannot be realistically captured by such models. The advantage of using agronomic calibration within a PMP model is that it combines the usefulness of agronomically-derived yield responses with the replication of an observed cropping pattern. The ability to account for observed behavior is often essential to the acceptability of model predictions by policymakers.

\footnotetext{
${ }^{16}$ See swap.ucdavis.edu.
} 


\section{Social costs of second-best policies: theory}

Let us denote by $\Pi(\mathbf{z}, \mathbf{r})$ the aggregate economic surplus from agricultural activities, where $\mathbf{z}$ is a vector of agricultural practices (acreages allocated to different crops, input intensities, etc.) and $\mathbf{r}$ is a vector of relevant exogenous prices. Denote by $E_{l}(\mathbf{z}), l=1, \ldots, L$ the net emissions of GHG $l$ associated with practices $\mathbf{z}$, where we allow for $L$ different GHGs. Denote by $E^{0}$ the aggregate agricultural emissions when there is no mitigation policy and $\mathbf{z}$ simply maximizes economic surplus. The first-best GHG reduction program can be written as

$$
\max _{\mathbf{z}} \Pi(\mathbf{z}, \mathbf{r}) \quad \text { subject to } \sum_{l=1}^{L} E_{l}(\mathbf{z}) \leq E^{0}-A \quad\left[\lambda^{*}\right]
$$

where $A$ is the emissions abatement target and $\lambda^{*}$ is the associated shadow price of carbon. We denote by $\Pi^{*}(A)$ the value function corresponding to program (1). If emissions are measurable, this allocation could be achieved in a decentralized fashion through a cap-and-trade program with cap equal to $E^{0}-A$, or alternatively by a per-unit tax on emissions equal to $\lambda^{*}{ }^{*}{ }^{17}$ The social cost (deadweight loss) of the abatement target is the reduction in economic surplus required to achieve the target, that is, $C^{*}(A)=\Pi^{*}(0)-\Pi^{*}(A)$. The marginal social cost of the first-best policy is equal to $\frac{d C^{*}}{d A}=-\frac{d \Pi^{*}}{d A}=\lambda^{*} \geq 0$.

Now suppose that the regulating agency can only choose among a set of policies $P \in \mathcal{P}$ to incentivize GHG abatement in a decentralized system. We view $P$ as a function of $\mathbf{z}$, such that if $P$ is implemented, the decentralized allocation must satisfy the constraints $P(\mathbf{z}) \leq 0$. Ignoring implementation costs, the second-best policy when the agency is limited to the set of policies $\mathcal{P}$ solves

$$
\max _{P \in \mathcal{P}} \Pi(\mathbf{z}, \mathbf{r}) \quad \text { subject to }\left\{\begin{array}{l}
\sum_{l=1}^{L} E_{l}(\mathbf{z}) \leq E^{0}-A \\
\mathbf{z} \in \operatorname{argmax}\{\Pi(\mathbf{z}, \mathbf{r}) \text { subject to } P(\mathbf{z}) \leq 0\}
\end{array} \quad\left[\lambda^{\mathcal{P}}\right]\right.
$$

with value function $\Pi^{\mathcal{P}}(A)$ satisfying $\Pi^{\mathcal{P}}(A) \leq \Pi^{*}(A)$ for all $A$. For example, if only GHG $l=1$ can be subject to a cap, the set of implementable policies is

\footnotetext{
${ }^{17}$ Formally, decentralization of the allocation can only be guaranteed under convexity of the abatement program.
} 
simply the set of possible caps on this GHG. The agency chooses the emission cap $\bar{E}_{1}$ to solve

$$
\max _{\bar{E}_{1}} \Pi(\mathbf{z}, \mathbf{r}) \quad \text { subject to }\left\{\begin{array}{l}
\sum_{l=1}^{L} E_{l}(\mathbf{z}) \leq E^{0}-A \\
\mathbf{z} \in \operatorname{argmax}\left\{\Pi(\mathbf{z}, \mathbf{r}) \text { subject to } E_{1}(\mathbf{z}) \leq \bar{E}_{1}\right\}
\end{array} .\right.
$$

The social cost (deadweight loss) of the second-best policy is $C^{\mathcal{P}}(A)=\Pi^{*}(0)-$ $\Pi^{\mathcal{P}}(A)$ and by construction $C^{\mathcal{P}}(A) \geq C^{*}(A)$. The associated marginal social cost is $\frac{d C^{\mathcal{P}}}{d A}=-\frac{d \Pi^{\mathcal{P}}}{d A}=\lambda^{\mathcal{P}} \geq 0$. The main objective of the following analysis is to derive estimates of the relative difference $\frac{C^{\mathcal{P}}(A)-C^{*}(A)}{C^{*}(A)}$ for a suite of second-best agricultural GHG mitigation policies.

\section{A regionalized model of California crop agri- culture}

Our empirical setting is the Central Valley, California's agricultural heartland. The Central Valley encompasses the Sacramento Valley (SV) in the north and the San Joaquin Valley (SJV) in the south. It is characterized by a diverse agricultural landscape, the prevalence of irrigation, regional water availability constraints, and a large number of annual and perennial crops.

To model crop choice, input intensity, tillage choice, and their links to GHG emissions, we adopt a structural programming approach, as in the pioneering studies of Adams et al. (1993) or McCarl and Schneider (2001). Like those authors, we rely on both observational data and agronomically derived information to calibrate our model. One difference, however, is that our PMP specification allows for the replication of economic information, in the form of regional cropping patterns, crop-level supply elasticities, and management practices.

\subsection{Model structure}

We assume that crop prices are exogenous, so that our economic optimization model maximizes the sum of regional agricultural profits subject to regional constraints on land and water availability, and agricultural profits align with social 
welfare. Unlike specialty crops, California field crops can be considered traded commodities with elastic residual demands. State supply is constrained by regional resource constraints and thus inelastic overall. Therefore, assuming perfectly elastic residual demands seems rather innocuous in our empirical context as abatement costs will be mostly borne by California producers. In Appendix D.4, we re-derive our main results assuming less than perfectly elastic residual demands and show that our GHG abatement cost measures are robust to this refinement. Considering less than perfectly elastic residual demands for the crops in our model slightly increases the size of social abatement costs due to the additional loss in (residual) consumer surplus. It does not significantly affect the abatement efficiency losses associated with the use of second-best policy instruments relative to the first best.

The production technology is specified through generalized CES production functions at the crop level. We explicitly model tillage choice by mapping tillage practices into a tillage index that represents the level of soil disturbance and is allowed to affect crop yields, operating costs, and GHG emission rates in a continuous fashion. The agronomic data we obtain from the DAYCENT model suggest that the effect of tillage intensity on crop yields is negligible in our empirical setting. Therefore, in practice we only allow for an effect of tillage intensity on per hectare costs and GHG emissions. ${ }^{18}$ The relationship between tillage practices and the tillage index is described in more detail in Appendix A.

Our regional model has $G=27$ regions, $I=7$ cropping activities, $J=3$ explicit inputs, and $L=3$ GHGs $\left(\mathrm{CO}_{2}, \mathrm{~N}_{2} \mathrm{O}\right.$, and $\left.\mathrm{CH}_{4}\right)$. For notational convenience let us write $G \equiv\{1, \ldots, G\}$ and similarly for sets $I, J$, and $L$. Let $j=1$ denote the land input, $j=2$ the water input, and $j=3$ the fertilizer input. GHG emissions from a hectare of cropland are allowed to vary according to the crop and the input and tillage intensities. The economic optimization model representing

\footnotetext{
${ }^{18}$ The use of tilling is rationalized in our model through the use of a crop-specific shadow benefit.
} 
the first-best policy can be written as follows:

$$
\begin{aligned}
& \max _{\mathbf{q}>0} \quad \Pi(\mathbf{q}, \mathbf{x}, \mathbf{T}) \equiv \sum_{g \in G} \sum_{i \in I}\left[p_{g i} q_{g i}-\left(c_{g i T}\left(T_{g i}\right)+\mu_{g i T} T_{g i}\right) x_{g i 1}\right.
\end{aligned}
$$

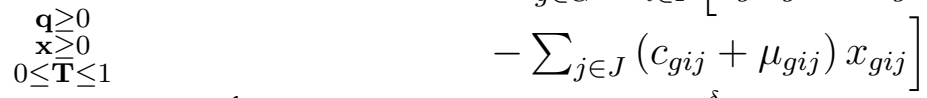

$$
\begin{aligned}
& \text { subject to } \begin{cases}q_{g i}=\alpha_{g i}\left(\sum_{j \in J} \beta_{g i j} x_{g i j}^{\rho_{g i}}\right)^{\frac{\delta_{g i}}{\rho_{g i}}} & \forall g, \forall i \\
\sum_{i \in I} x_{g i j} \leq b_{g j} & {\left[\lambda_{g j}\right] \quad \forall g, j=1,2} \\
\sum_{g \in G} \sum_{i \in I} x_{g i 1}\left[\sum_{l \in L} e_{g i l}\left(\frac{x_{g i 2}}{x_{g i 1}}, \frac{x_{g i 3}}{x_{g i 1}}, T_{g i}\right)\right] \leq \hat{\mathcal{E}} \quad\left[\lambda^{*}\right] & \end{cases}
\end{aligned}
$$

where $\mathbf{q}=\left(q_{g i}\right)_{(g, i) \in G \times I}$ denotes output quantities, $\mathbf{x}=\left(x_{g i j}\right)_{(g, i, j) \in G \times I \times J}$ denotes allocated inputs, and $\mathbf{T}=\left(T_{g i}\right)_{(g, i) \in G \times I}$ denotes tillage intensities. The parameter $p_{g i}$ is the regional price of crop $i$ and $c_{g i j}$ denotes the regional price of input $j$ in activity $i$. We assume that all inputs except the water and fertilizer inputs and those related to tillage are employed in fixed proportions with land, hence we include their respective costs in the land cost $c_{g i 1}$. Similarly, we assume that all fertilizer elements (N, P, K, and others) are employed in fixed proportions for a given crop so that the price of $\mathrm{N}$ fertilizer $c_{g i 3}$ includes all fertilizer costs. Because fertilizer elements are used in different proportions for different crops, $c_{g i 3}$ is crop-specific. The water price $c_{g i 2}$ is the same for all crops in a given region. The functions $c_{g i T}\left(T_{g i}\right)$ describe the per hectare costs of tillage and are region- and crop-specific. The parameters $b_{g 1}$ and $b_{g 2}$ denote the regional land and water availabilities, respectively, and $\lambda_{g j}$ denotes the associated shadow price. The parameters of the crop-level generalized CES production functions satisfy $\alpha_{g i}>0, \beta_{g i j}>0, \sum_{j} \beta_{g i j}=1, \rho_{g i} \in(-\infty, 0) \cup(0,1)$, and $\delta_{g i} \in(0,1)$.

Calibration parameters $\mu_{g i j}(j=1, \ldots, 3)$ are added to the per unit input costs so as to replicate the input allocation observed in the baseline (Mérel et al., 2014). Similarly, a calibration parameter $\mu_{\text {giT }}$ is added to the tillage cost to allow calibration of the baseline tillage technology.

The term $e_{\text {gil }}$ represents the regional emission factor for crop $i$ and GHG $l$ expressed in metric tonnes of $\mathrm{CO}_{2}$ equivalent per hectare. Emission factors are specified as quadratic functions of the water, fertilizer, and tillage intensities that allow for interactions; their empirical estimation is explained in Appendix B. Total GHG emissions are constrained by an exogenous emission cap denoted $\hat{\mathcal{E}}$. 


\subsection{Model calibration}

We only provide an overview of the calibration procedure here; details are given in Appendix C. The production model is calibrated to a reference year with no emission cap $(\hat{\mathcal{E}} \rightarrow+\infty)$. Each region is calibrated independently of all others, and we drop the regional index $g$ to streamline the notation.

We call reference conditions the economic environment under which social surplus is being maximized in the reference year. The reference conditions are a vector $\boldsymbol{\nu}=(\mathbf{p}, \mathbf{c}, \mathbf{b})$ of crop prices $\mathbf{p}=\left(p_{1}, \ldots, p_{I}\right)$, input costs $\mathbf{c}=\left(c_{11}, c_{12}, c_{13}, c_{1 T}, \ldots, c_{I T}\right)$, and resource availabilities $\mathbf{b}=\left(b_{1}, b_{2}\right)$. These reference conditions are observed in our dataset, with the exception of the tillage cost functions $c_{i T}\left(T_{i}\right)$ which are estimated using data and expert opinion on the field-level practices associated with various degrees of tillage intensity. Per hectare costs of tillage practices are matched with corresponding levels of soil disturbance, and a quadratic curve is fitted through the resulting points to identify the function $c_{i T}$.

The calibration information that the model should replicate under the reference conditions $\boldsymbol{\nu}$ is a vector $\overline{\boldsymbol{\psi}}=\left(\overline{\mathbf{q}}, \overline{\mathbf{x}}, \overline{\mathbf{T}}, \overline{\mathbf{y}}_{2}, \overline{\mathbf{y}}_{3}, \overline{\boldsymbol{\sigma}}, \overline{\boldsymbol{\eta}}, \overline{\boldsymbol{\lambda}}\right)$ of reference outputs $\overline{\mathbf{q}}=\left(\bar{q}_{1}, \ldots, \bar{q}_{I}\right)$, input allocations $\overline{\mathbf{x}}=\left(\bar{x}_{11}, \bar{x}_{12}, \ldots, \bar{x}_{I 3}\right)$, tillage intensities $\overline{\mathbf{T}}=\left(\bar{T}_{1}, \ldots, \bar{T}_{I}\right)$, yield elasticities with respect to water $\overline{\mathbf{y}}_{2}=\left(\bar{y}_{12}, \ldots, \bar{y}_{I 2}\right)$, yield elasticities with respect to $\mathrm{N}$ fertilizer $\overline{\mathbf{y}}_{3}=\left(\bar{y}_{13}, \ldots, \bar{y}_{I 3}\right)$, substitution elasticities $\overline{\boldsymbol{\sigma}}=\left(\bar{\sigma}_{1}, \ldots, \bar{\sigma}_{I}\right)$, supply elasticities $\overline{\boldsymbol{\eta}}=\left(\bar{\eta}_{1}, \ldots, \bar{\eta}_{I}\right)$, and shadow values of resource constraints $\overline{\boldsymbol{\lambda}}=\left(\bar{\lambda}_{1}, \bar{\lambda}_{2}\right)$. Part of this calibration information is observed in our dataset $(\overline{\mathbf{q}}, \overline{\mathbf{x}}$, and $\overline{\mathbf{T}})$, part of it is obtained through the use of the biogeochemical model DAYCENT $\left(\overline{\mathbf{y}}_{2}, \overline{\mathbf{y}}_{3}\right.$, and $\left.\overline{\boldsymbol{\sigma}}\right)$, part of it comes from previous studies $(\overline{\boldsymbol{\eta}})$, and the rest is derived endogenously $(\overline{\boldsymbol{\lambda}})$.

Our dataset includes observational information on crop acreages, irrigation and fertilizer intensities, and yields. Given the low incidence of reduced tillage practices in California (Mitchell et al., 2007), we assume that the reference tillage intensity for all crops is California conventional tillage, corresponding to a soil disturbance value of 0.91 on a scale from 0 to 1 . The DAYCENT model is used to generate crop yields conditional on irrigation intensity, $\mathrm{N}$ fertilizer, and tillage intensity in each region. We use this information to construct partial yield response functions, varying one factor at a time while holding the others at their 
reference values. As indicated above, the yield responses to tillage are essentially flat, and therefore we assume that tillage only affects per hectare costs and GHG emission rates. Partial yield response functions for irrigation and $\mathrm{N}$ fertilizer are used to calculate the reference yield elasticities with respect to water and $\mathrm{N}$ fertilizer intensities. The agronomic partial yield response functions are also used to calibrate region- and crop-specific substitution elasticities as detailed in Appendix D.1. ${ }^{19}$

To calibrate crop-level supply elasticities, we use the methodology developed by Mérel et al. (2011) and Garnache and Mérel (2015). These authors show that not all vectors of supply elasticities $\overline{\boldsymbol{\eta}}$ can be replicated by model (2), and that the reference cropping pattern $(\overline{\mathbf{q}}, \overline{\mathbf{x}})$ determines the set of reproducible elasticities conditional on model structure. Therefore, starting from a vector of statewide elasticity priors, we modify it so as to allow for exact calibration in each region. ${ }^{20}$

Finally, following Garnache et al. (2016) we choose the reference shadow value of land $\bar{\lambda}_{1}$ (resp. water $\bar{\lambda}_{2}$ ) so as to minimize the sum of squared shadow expenditures $\sum_{i}\left(\mu_{i 1} \bar{x}_{i 1}\right)^{2}$ (resp. $\left.\sum_{i}\left(\mu_{i 2} \bar{x}_{i 2}\right)^{2}\right)$ required to make the model calibrate. As a robustness check, we also use the traditional method of Howitt (1995b) to set reference shadow values. ${ }^{21}$

Using obvious notation, the calibration problem consists of choosing the model parameters $(\boldsymbol{\alpha}, \boldsymbol{\beta}, \boldsymbol{\rho}, \boldsymbol{\delta}, \boldsymbol{\mu})$ so as to replicate $\overline{\boldsymbol{\psi}}$ under conditions $\boldsymbol{\nu}$. The model is exactly identified so that exact replication of the reference information is achieved by a uniquely determined model parameterization.

\subsection{Information sources}

The spatial resolution of our model is based on the SWAP model. The SWAP model is a programming representation of crop agriculture across 27 regions of the Central Valley. These regions match water districts boundaries and thus capture meaningful regional water constraints. The SV covers 10 regions, denoted 1

\footnotetext{
${ }^{19}$ In Appendix D.1, we also conduct sensitivity analysis with respect to the choice of substitution elasticities. This choice affects the absolute abatement cost estimates of various policies, but not their relative rankings.

${ }^{20}$ In Appendix D.2, we conduct sensitivity analysis with respect to the choice of supply elasticities. Our results are robust to alternative sets of prior supply elasticities.

${ }^{21}$ See Appendix D.3.
} 
through 9, while the SJV encompasses 17 regions, denoted 10 through $21 \mathrm{C}$.

Our study includes seven major crop groups covering 1.29 million hectares (3.18 million acres) in 2005. Nearly 1 million hectares of modeled cropland are located in the SJV. The crop acreage covered in this study represents $70 \%$ of the 2005 non-tree agricultural acreage in the Central Valley. We do not include tree crops because the DAYCENT model is not calibrated for these crops. The DAYCENT model is not able to simulate flooded systems, therefore rice production is also excluded. The acreage distribution among modeled crops is shown in Table 1. The "grain" group is represented by wheat and the "other field crops" group by sunflower, and in the remainder of the paper we refer to these groups by their representative crop. The fact that we are only able to represent a subset of the crops currently grown in the Central Valley means that our results should be interpreted as an upper bound on the social costs of agricultural GHG mitigation, as we are ignoring mitigation possibilities associated with acreage substitution with excluded crops and changes in production practices for excluded crops.

Table 1 Acreage shares in our cropping system (\%)

\begin{tabular}{lccc}
\hline Crop & Central Valley & Sacramento Valley & San Joaquin Valley \\
\hline Alfalfa & 22.0 & 24.2 & 21.3 \\
Corn & 21.0 & 22.3 & 20.6 \\
Cotton & 20.9 & 0.8 & 27.0 \\
Grain (Wheat) & 11.5 & 20.6 & 8.7 \\
Other field crops (Sunflower) & 13.6 & 9.0 & 15.0 \\
Processing tomatoes & 9.5 & 17.5 & 7.1 \\
Safflower & 1.5 & 5.6 & 0.3 \\
\hline Total & 100.00 & 100.00 & 100.00 \\
\hline
\end{tabular}

Crop acreages for 2005 come from the California DWR. Water prices come from the SWAP model and represent a weighted average of delivery prices from the Central Valley Project and the State Water Project, local surface water costs, and estimated groundwater pumping costs. Crop prices and yields for 2005 come from the County Agricultural Commissioner Reports and are aggregated at the level of SWAP regions by taking account of the land of each county present in a given region. ${ }^{22}$ Input application rates and costs come from the Agricultural cost

\footnotetext{
${ }^{22}$ Yields are constructed using acreage weights while prices are constructed using output
} 
and return studies, which provide information on observed regional production practices over broad regions, typically the SV or SJV. ${ }^{23}$ Own-price supply elasticity priors come from the SWAP model and are reported in Appendix C, Table C.3.

The DAYCENT model is used to generate yields and GHG emission factors conditional on input and tillage intensities. Appendix B describes in detail how the DAYCENT model output is generated and processed.

After calibration, predicted net GHG emissions for our agricultural system in the reference allocation amount to $3.38 \mathrm{MtCO}_{2} \mathrm{e}$ per year, the majority of which$3.18 \mathrm{MtCO}_{2}$ - comes from $\mathrm{N}_{2} \mathrm{O}$ emissions. This figure seems consistent with $\mathrm{N}_{2} \mathrm{O}$ emissions reported in CARB's latest GHG inventory for agricultural soil management (cropping) in California (CARB, 2014a). CARB estimates $\mathrm{N}_{2} \mathrm{O}$ emissions from agricultural soil management to be $8.8 \mathrm{MtCO}_{2} \mathrm{e}$ in 2012 , and their figure includes all cropland uses. According to the USDA National Agricultural Statistics Service, California cropland was about 2.82 million hectares in 2012, amounting to an $\mathrm{N}_{2} \mathrm{O}$ emission intensity of $3.12 \mathrm{tCO}_{2} \mathrm{e} /$ ha. ${ }^{24}$ Our implied $\mathrm{N}_{2} \mathrm{O}$ emissions intensity is $2.47 \mathrm{tCO}_{2} \mathrm{e} / \mathrm{ha}$ and is therefore in line with that for California crop agriculture as a whole.

\subsection{Model validation}

For the purpose of validation, we use the production side of our model, calibrated to 2005 economic and biophysical information, to predict acreage allocations in 2010, the only other recent year for which we have access to detailed acreage information at the level of SWAP regions (from the California DWR). We construct measures of region-level expected crop prices for 2010 from county-level information on prices, using county-level information on yields and the acreage of each county present in a given SWAP region to derive output weights. Besides crop prices, the 2010 economic environment includes updated water prices (obtained from the updated version of SWAP) and fertilizer prices (constructed using

weights.

${ }^{23}$ These production practices are representative of conventional agriculture. See coststudies.ucdavis.edu.

${ }^{24}$ See www.nass.usda.gov. 
prices published in the USDA-NASS database for urea fertilizer). We include an additional constraint on processing tomato output at the level of the Central Valley to capture the limited capacity of tomato processing plants in the short run (Carter, 2006). This constraint allows for a reallocation of tomato production across regions while keeping total production at or below the 2005 level. It is not present in the GHG emission abatement scenarios because in the long run, processing capacity could expand. Consistent with our GHG abatement simulations, we keep regional land and water availability constraints at their 2005 levels, which amounts to neglecting resource reallocation between modeled activities and activities outside our cropping system, such as tree crops.

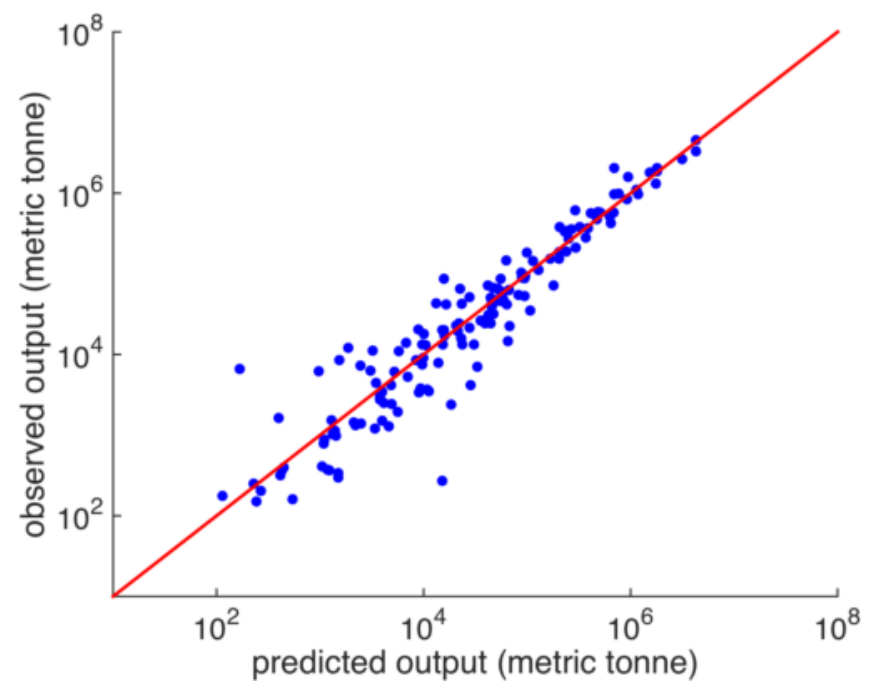

Figure 1 Predicted crop outputs for each SWAP region against observed crop outputs for 2010

Note: The 45-degree line is shown in red. Axes use a logarithmic scale.

Figure 1 plots predicted 2010 output by crop for each SWAP region against actual 2010 output. Each dot represents the output of a crop in a given SWAP region. The actual 2010 output is calculated by multiplying observed 2010 acreage in each region by the 2010 region-level yield. The 2010 region-level yield is computed using county-level yields for 2010 and the acreage of each county present in a given SWAP region. A regression of predicted 2010 output on actual 2010 output, with a constant, yields a coefficient estimate of 0.98 with a standard error (clustered at the region level) of 0.09 and an R-squared of 0.92 . The positive and 
statistically significant estimate on the slope parameter suggests that overall, our model is capable of predicting crop outputs with reasonable accuracy.

Table 2 Observed and predicted relative changes in acreage (\%)

\begin{tabular}{lcccccccc}
\hline \multirow{2}{*}{ Crop } & \multicolumn{2}{c}{ Central Valley } & & \multicolumn{2}{c}{ Sacramento Valley } & & \multicolumn{2}{c}{ San Joaquin Valley } \\
\cline { 2 - 3 } & Observed & Predicted & & Observed & Predicted & & Observed & Predicted \\
\hline Alfalfa & -4 & -14 & & 0 & -19 & & -6 & -12 \\
Corn & 14 & 7 & & 16 & 27 & & 13 & 0 \\
Cotton & -57 & -29 & & -46 & -32 & & -57 & -29 \\
Wheat & 9 & 2 & & -6 & -1 & & 20 & 4 \\
Sunflower & 33 & 48 & & 0 & -2 & & 39 & 57 \\
Proc. tom & -1 & -2 & & -22 & -8 & & 15 & 2 \\
Safflower & -17 & 15 & & -28 & 7 & & 41 & 58 \\
\hline
\end{tabular}

Because net GHG emissions from our cropping system largely depend on how agricultural acreage is allocated across crops with varying levels of emissions intensity per hectare (the extensive margin), a key question for our GHG abatement analysis is how well the model can predict crop-level acreage changes between the baseline and an out-of-sample year. Table 2 reports predicted and observed relative changes in acreage between 2005 and 2010 for each crop, aggregated at the levels of the SV, the SJV, and the Central Valley. Most predicted acreage changes have the right sign, except for safflower, which however represents only $1.5 \%$ of the modeled acreage in the Central Valley. Notably, our model is able to predict a large share of the vast decline in cotton acreage between 2005 and 2010, as well as some of the observed reallocation of processing tomato acreage from the SV towards the SJV. Taken together, these validation tests appear reassuring with respect to the model's ability to capture relevant tradeoffs at the regional scale.

\section{California agriculture's GHG mitigation po- tential}

The GHG mitigation potential of California's Central Valley can be summarized by the marginal abatement cost schedule obtained under the first-best program (2) as the shadow value of the GHG emission constraint. By iteratively decreasing 
the cap on total GHG emissions $\hat{\mathcal{E}}$, we derive the marginal social cost curve and the associated changes in land use and production practices. ${ }^{25}$

In terms of decentralized implementation, program (2) implicitly assumes that the regulating agency has perfect knowledge of the emission generation process. Because of the regional aggregation level of the economic data at our disposal, we can at best model emissions at the level of the 27 Central Valley regions. The resulting abatement schedule thus corresponds to a "feasible" first-best policy in the sense that we use the finest spatial resolution possible given our dataset. Furthermore, in this section we focus on the opportunity costs directly incurred by farmers in terms of reduced farm profits and abstract from transaction costs and the costs of administering the incentive program.

\subsection{Abatement under the first-best policy}

The marginal social cost of GHG abatement in our cropping system is depicted in Figure 2 for an emission cap ranging from 100\% down to $44 \%$ of baseline emissions. The figure shows the contributions of each of the three GHGs to overall abatement. Over the abatement range investigated here, total GHG abatement in California agriculture appears to be relatively inelastic, as confirmed by the fit of a constant-elasticity function to the empirical marginal abatement cost curve, which yields an elasticity of 0.74. Appendices D.1, D.2, and D.3 report marginal social cost schedules obtained under alternative assumptions on substitution elasticities, prior supply elasticities, and baseline shadow values, while Appendix D.4 allows for endogenous crop prices.

At a price of $\$ 20 / \mathrm{tCO}_{2} \mathrm{e}$, the price anticipated by CARB in 2020, our model forecasts that field crop agriculture in the Central Valley would supply 1.03 $\mathrm{MtCO}_{2} \mathrm{e}$ of GHG abatement per year, corresponding to a $30 \%$ reduction in baseline emissions, for a total social cost representing $0.44 \%$ of baseline agricultural profits.

This predicted abatement seems consistent with the range of estimates available for other U.S. regions, suggesting that California's field crop agriculture could

\footnotetext{
${ }^{25}$ We obtain the exact same curve when modeling an iteratively increasing tax on GHG emissions, suggesting that over the range of abatement considered, non-convexities in the emission process do not prevent first-best allocations from being decentralized.
} 


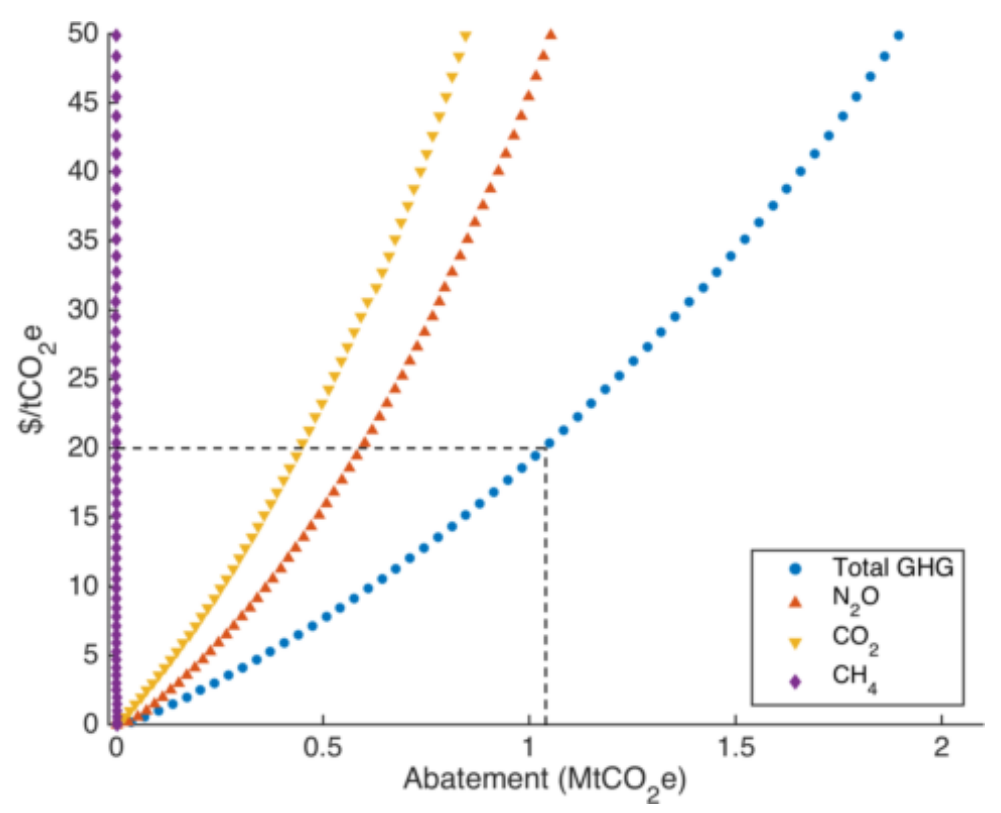

Figure 2 Marginal abatement cost under the first-best policy and contribution of each GHG

Note: The dashed line indicates the CARB predicted price of $\$ 20 / \mathrm{tCO}_{2} \mathrm{e}$ in 2020 .

competitively reduce GHG emissions relative to other U.S. agricultural sectors (e.g., McCarl and Schneider (2001); Pautsch et al. (2001); Antle and Ogle (2012)).

Our first-best supply schedule also suggests that the agricultural sector could play a role in reducing GHG emissions in California. Bailey et al. (2013) estimate that the more likely carbon price to emerge under CARB's allowance trading program corresponds to the reserve price, which is expected to reach about $\$ 20 / \mathrm{tCO}_{2} \mathrm{e}$ by 2020 . More specifically, they report an $80 \%$ probability of the allowance price settling near or at the reserve price, and thus a $20 \%$ probability of a substantially higher price. Caron et al. (2015) find allowance prices in 2020 ranging from $\$ 12$ to $61 \$ / \mathrm{tCO}_{2} \mathrm{e}$ depending on whether electricity tariffs are adopted, legislation is introduced to prevent resource shuffling, and permit trading with the EU ETS is allowed. The authors' highest allowance price of $\$ 61 / \mathrm{tCO}_{2} \mathrm{e}$ corresponds to the current features of California's cap-and-trade program. Although the magnitude of the GHG abatement derived for our agricultural system is modest relative to the statewide abatement target of about $80 \mathrm{MtCO}_{2} \mathrm{e}$ in 2020 , so are many of the abatement levels provided by individual measures adopted or 
envisaged by CARB in order to implement AB 32 (CARB, 2010b). For instance, measures pertaining to solar roofs, solar hot water, landfill methane control, or motor vehicle refrigerant emissions are each expected to yield GHG savings below 1.5 $\mathrm{MtCO}_{2} \mathrm{e}$ (CARB, 2010a). Given that our model only captures part of California cropping systems, our abatement figure suggests that crop agriculture could be part of a multi-facet approach to reducing state-level GHG emissions, subject to the caveat that this abatement potential can be elicited through second-best instruments at a reasonable additional social cost.

Although carbon sequestration often plays a dominant role in GHG emission mitigation from agricultural land (Lal et al., 1998; McCarl and Schneider, 2001), our findings suggest that $\mathrm{N}_{2} \mathrm{O}$ would contribute the majority of abatement in California's Central Valley with $57 \%$ of total abatement at a social price of $\$ 20 / \mathrm{tCO}_{2} \mathrm{e}$, while the contribution of carbon sequestration lies at $43 \%$ and that of $\mathrm{CH}_{4}$ is negligible. ${ }^{26}$ This result stands in contrast to previous estimates of technical abatement potential reported by De Gryze et al. (2011) for field crops in California. Based on the same biophysical model as ours, these authors attribute a larger share of the technical GHG abatement potential in California to increased soil carbon sequestration, with changes in $\mathrm{N}_{2} \mathrm{O}$ playing a secondary role. However, their study differs from ours in three important respects. First, De Gryze et al. (2011) do not account for opportunity costs and impose changes in agricultural practices exogenously. Second, they focus on crop management practices and assume that crop acreages remain constant. Third, they consider cover cropping and manure application as additional management practices. Such practices tend to affect soil carbon more than emissions of $\mathrm{N}_{2} \mathrm{O}$.

Under the first-best policy, GHG abatement per hectare of cropland varies substantially across the 27 Central Valley regions. Figure 3 illustrates these differences by showing the abatement achieved in each region at a marginal cost of $\$ 20 / \mathrm{tCO}_{2} \mathrm{e}$, expressed per hectare of regional baseline cropland. The per-hectare abatement ranges from 0.026 (region $15 \mathrm{~B}$ ) to $1.37 \mathrm{tCO}_{2} \mathrm{e} /$ ha/year (region $14 \mathrm{~A}$ ). There appears to be a clear difference in abatement between the eastern and western parts of the Central Valley, with higher abatement levels per hectare elicited

\footnotetext{
${ }^{26}$ The contribution of $\mathrm{CH}_{4}$ to total abatement would substantially increase if rice were included in the study.
} 


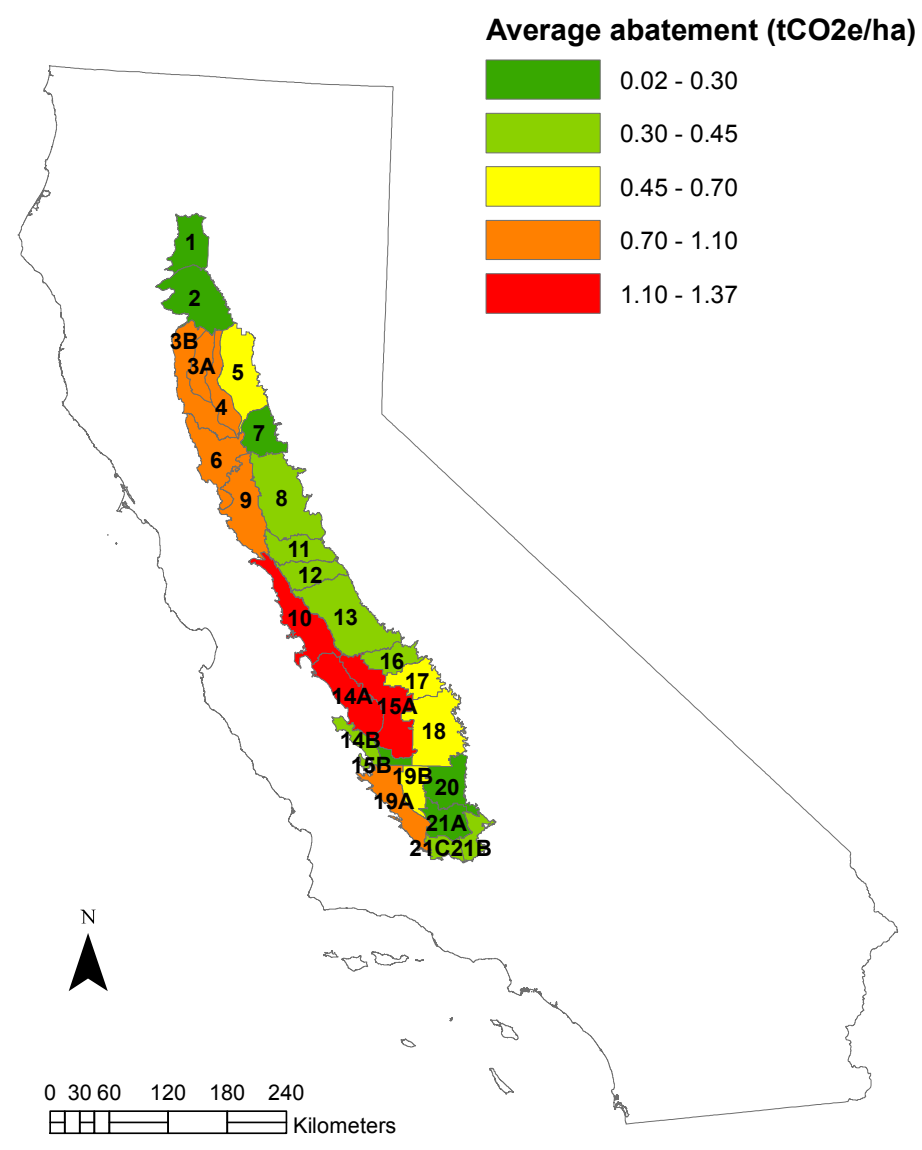

Figure 3 Regional GHG emission abatement per year at $\$ 20 / \mathrm{tCO}_{2}$ e per hectare of baseline cropland

in the western part. In fact, most of the spatial heterogeneity in abatement intensity can be attributed to two factors acting in concert: regional differences in the observed crop mix and regional heterogeneity in the emission factor functions $e_{\text {gil }}$. Further discussion of the spatial heterogeneity in crop-specific emission rates in the baseline and at a marginal cost of $\$ 20 / \mathrm{tCO}_{2} \mathrm{e}$ is provided in Appendix E.1. 


\subsection{Intensive and extensive margin contributions}

Figure 4 depicts the acreage allocation response reflecting adjustments at the extensive margin. Overall, our model predicts that farmers respond to more stringent emission caps by substituting acreage away from crops with high emission rates and low baseline gross revenue such as sunflower and towards crops with low emission rates such as wheat and alfalfa. Crops with high emission rates but high baseline gross revenues such as processing tomatoes experience only small variations in acreage, as do crops characterized by low to moderate emission rates and gross revenues such as safflower and corn. The model predicts an important decrease in the acreage planted in cotton, a crop with a high gross revenue per hectare but a high emission rate and limited possibilities of abatement through changes in management practices.

GHG emission caps also affect the total agricultural land base, although this effect happens to be quite small. Our model predicts a mere $2.5 \%$ loss of cropland relative to the baseline under the most stringent cap, i.e., $44 \%$ of baseline emissions. At a marginal social price of $\$ 20 / \mathrm{tCO}_{2} \mathrm{e}$, the loss of cropland is $2.4 \%$. Because we assume zero emissions from land not used for any of the cropping activities considered in the model, we may be slightly overestimating the abatement potential of our agricultural system.

In order to illustrate the relative importance of adjustments along the intensive and extensive margins under the first-best policy, we decompose total abatement into the abatement obtained when holding crop acreages at their baseline levels (intensive margin) and that obtained when holding the input and tillage intensities at their baseline levels (extensive margin). That is, we define the intensive and extensive margin contributions to total abatement as follows:

$$
\underbrace{\Delta \hat{\mathcal{E}}}_{\text {total abatement }} \approx \underbrace{\sum_{g \in G} \sum_{i \in I} \bar{x}_{g i 1} \times \underbrace{\sum_{l \in L} \Delta e_{g i l}}_{\text {emission rate change }}}_{\text {intensive margin }}+\underbrace{\sum_{g \in G} \sum_{i \in I} \underbrace{\Delta x_{g i 1}}_{\text {acreage change }} \times \sum_{l \in L} \bar{e}_{g i l}}_{\text {extensive margin }}
$$

where bars denote baseline levels and $\Delta$ denotes the change in a variable in response to a given GHG emission cap under the first best. 


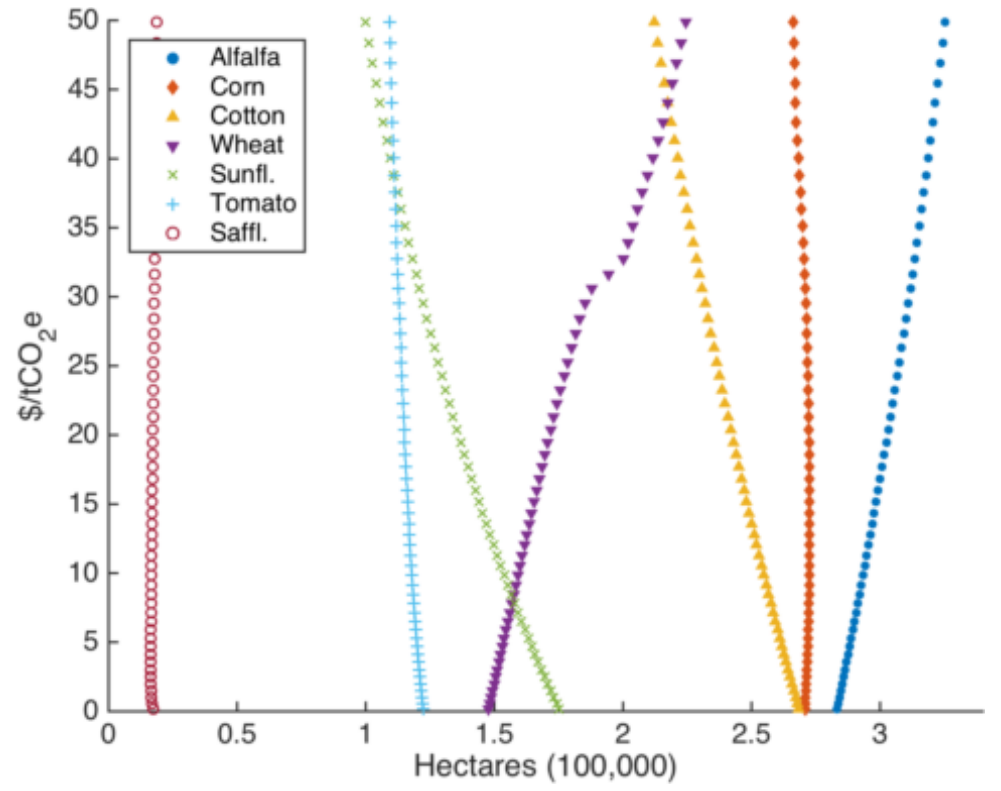

Figure 4 Changes in the crop mix under the first-best policy

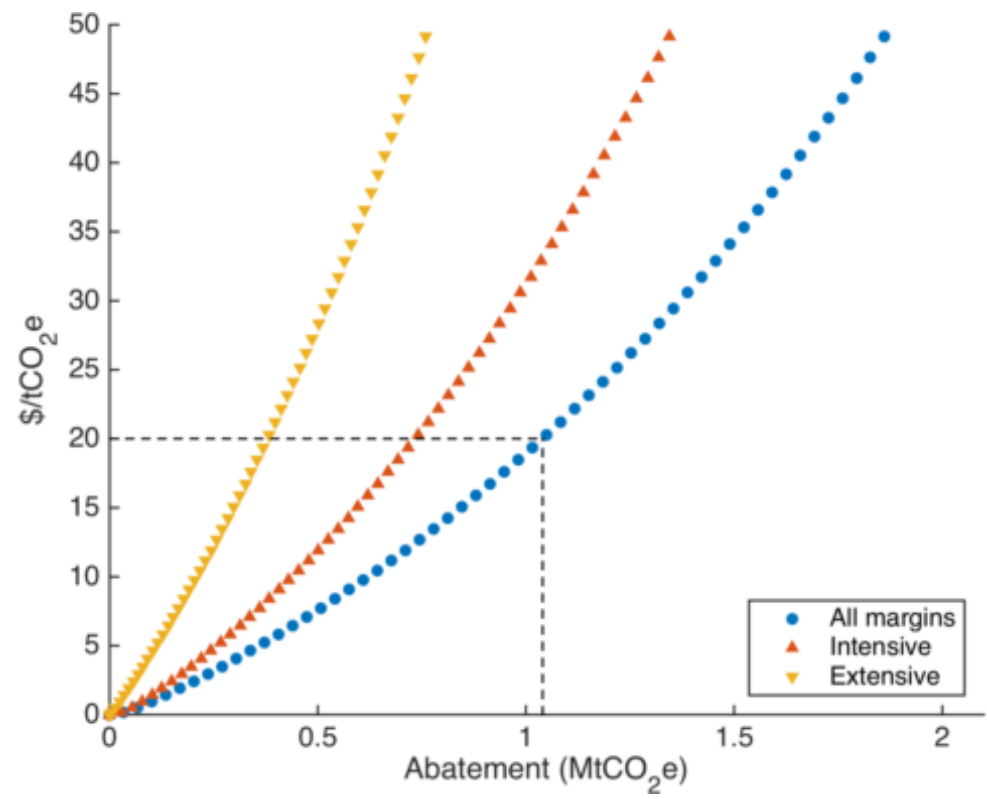

Figure 5 Marginal social abatement cost curve and intensive and extensive margin contributions 
Figure 5 depicts the resulting decomposition of the abatement schedule into the two adjustment margins. ${ }^{27}$ Adjustments along the intensive margin dominate the extensive margin, contributing to almost all of the abatement at low marginal social costs and to $71 \%$ of total abatement at a marginal social cost of $\$ 20 / \mathrm{tCO}_{2} \mathrm{e}$. Indeed, at very low abatement levels, for some crops reductions in $\mathrm{N}$ fertilizer intensities can contribute to lower GHG emissions while having only minimal effects on yields. This is the case for wheat in the SJV and for sunflower, and to a smaller extent for wheat in the SV and for cotton in the SJV, as their yield response to $\mathrm{N}$ fertilization is relatively flat around the baseline (see Figure C.1) while their emissions are positively correlated with $\mathrm{N}$ application (see Figure B.1). Therefore, reductions in $\mathrm{N}$ intensity represent a low hanging fruit for $\mathrm{GHG}$ emission reductions at low abatement targets. Reductions in tillage intensity and acreage reallocation play a significant role at higher abatement targets.

\section{Social costs of second-best policies: empirical evidence}

Because direct GHG emission measurements are not feasible for agricultural fields, a first-best policy would need to provide abatement incentives to agents by targeting the field management actions that contribute to abatement. Although such a policy would minimize the direct opportunity costs of achieving a given abatement, for reasons highlighted in Section 1 it may be administratively costly or politically difficult to implement. In this section, we derive marginal social abatement cost curves for a series of second-best policies with arguably lower implementation costs, namely policies incentivizing emission reductions using spatially aggregated emission factors, policies regulating emissions of a single GHG, and policies regulating one input or a combination of inputs. We use the definitions laid out in Section 2 when referring to the social costs of these policies.

\footnotetext{
${ }^{27}$ Changes in input and tillage intensities and yields at a marginal social cost of $\$ 20 / \mathrm{tCO}_{2} \mathrm{e}$ for the SV and the SJV are discussed in Appendix E.2.
} 


\subsection{Spatially aggregated emission factors}

Under the feasible first-best policy, "actual" emissions were inferred using the most disaggregated information available, namely at the level of each of the 27 regions of the Central Valley. In the following scenario, the conditional GHG emission rates simulated by the DAYCENT model are instead aggregated up to either the SV and SJV levels or to the level of the entire Central Valley using regional crop acreages as weights. We then re-estimate valley-level quadratic emission response functions, say $\tilde{e}_{v i l}$ (where $v$ indexes the valley), as detailed in Appendix B. All regions $g$ included in the same valley $v(g)$ then have the same conditional emission factors $\tilde{e}_{v(g) i l}$ and would be rewarded identically under a practice-based incentive schedule relying on those factors.

Spatially aggregated emission factor functions are meant to capture the average relationship between practices and emission rates over broadly defined regions. A policy relying on such factors would arguably entail both lower knowledge acquisition costs and lower enforcement costs than the first best. Knowledge acquisition costs would be reduced as this approach eliminates the need to derive locally explicit emission factors. For instance, when deriving emission factors the biophysical model could be run for average soil and climate conditions, reducing the number of simulations and the range of conditions for which the model should be calibrated and validated. Enforcement costs would also be reduced as agents' actions within a broadly defined region would be monitored against a common schedule. Finally, the policy might be politically attractive as it would entail the even treatment of farmers located within broad regions.

In our model, the second-best policy relying on valley-aggregated emission 
factors can be represented by the following program:

$$
\begin{aligned}
& \max _{\hat{E}} \Pi(\mathbf{q}, \mathbf{x}, \mathbf{T}) \\
& \int \sum_{g \in G} \sum_{i \in I} x_{g i 1}\left[\sum_{l \in L} e_{g i l}\left(\frac{x_{g i 2}}{x_{g i 1}}, \frac{x_{g i 3}}{x_{g i 1}}, T_{g i}\right)\right] \leq \hat{\mathcal{E}} \quad\left[\lambda^{\mathcal{P}}\right] \\
& (\mathbf{q}, \mathbf{x}, \mathbf{T}) \in \operatorname{argmax} \Pi(\mathbf{q}, \mathbf{x}, \mathbf{T}) \\
& \text { s. to } \\
& \text { s. to } \begin{cases}q_{g i}=\alpha_{g i}\left(\sum_{j \in J} \beta_{g i j} x_{g i j}^{\rho_{g i}}\right)^{\frac{\delta_{g i}}{\rho_{g i}}} & \forall g, \forall i \\
\sum_{i \in I} x_{g i j} \leq b_{g j} & \forall g, j=1,2 \\
\sum_{g \in G} \sum_{i \in I} x_{g i 1}\left[\sum_{l \in L} \tilde{e}_{v(g) i l}\left(\frac{x_{g i 2}}{x_{g i 1}}, \frac{x_{g i 3}}{x_{g i 1}}, T_{g i}\right)\right] \leq \hat{E}\end{cases}
\end{aligned}
$$

and the restricted marginal social cost is equal to the shadow price on the emission cap of the outer program, $\lambda^{\mathcal{P}}$. The marginal cost curve is "restricted" in the sense that compared to the first-best program (2), program (4) constrains the choice variables to be profit-maximizing under an emission cap constructed using the coarse, valley-aggregated emissions factors $\tilde{e}_{v i l}$ instead of the finer, and more accurate ones.

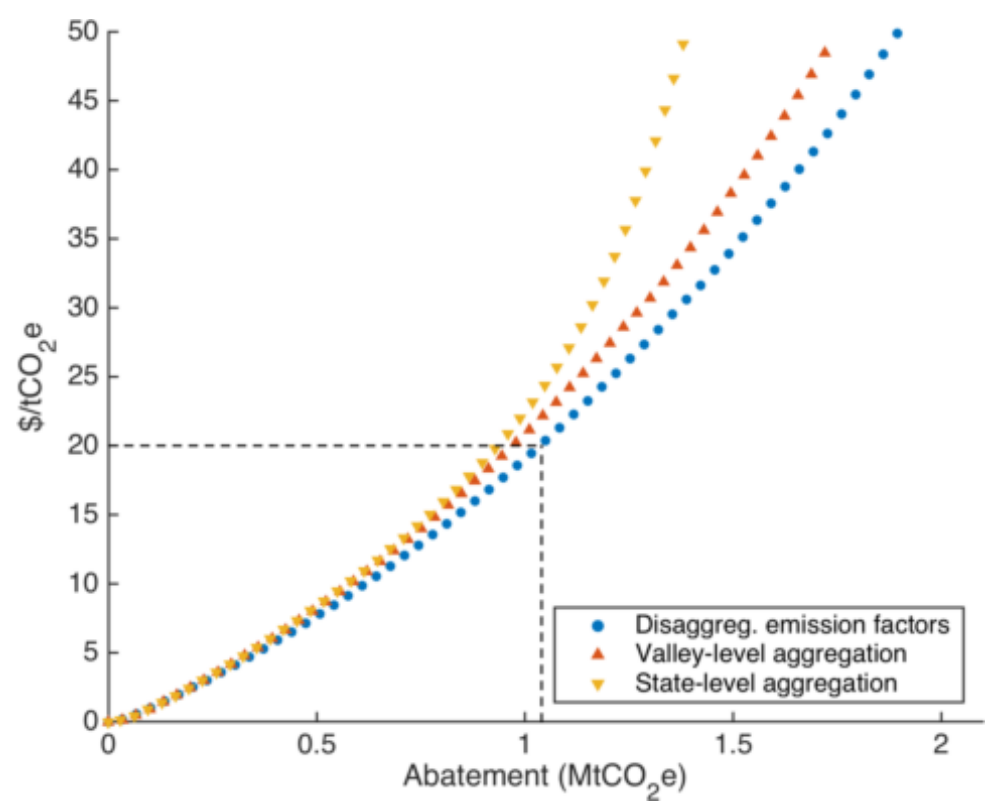

Figure 6 Marginal abatement costs under the first-best policy and second-best policies with valley- and state-level emission factors 
The restricted marginal social cost curves obtained under the two alternative aggregation levels happen to be very close to the first-best schedule, at least for low to moderate abatement levels, as illustrated in Figure 6. The social costs associated with a $1 \mathrm{MtCO}_{2}$ e abatement are $0.44 \%$ and $0.45 \%$ of baseline agricultural profits using the valley- and state-level emission factors, respectively. These figures correspond to an increase of less than $8 \%$ relative to the social cost of the first-best policy. Viewed differently, the loss in emission abatement under state-level emission factors at a social price of $\$ 20 / \mathrm{tCO}_{2}$ e represents less than $10 \%$ of the abatement obtained under the first-best policy. At high marginal social costs, the state-level aggregation is associated with larger efficiency losses, while the valley-level aggregation still performs relatively well. Although our first-best schedule was constructed using emission factors that are already aggregated over water regions, these findings suggest that the distortions arising from policies using spatially aggregated conditional emission factors instead of local ones may be acceptable in California. A likely reason for these findings is that despite some heterogeneity in absolute baseline emission rates, most regions have the same lowest- and highest-emitting crops (wheat and alfalfa, and sunflower and processing tomatoes, respectively), and crop-level emission rates generally respond in the same direction to marginal changes in input intensities, notably in $\mathrm{N}$ fertilizer and tillage intensities.

\subsection{Single GHG incentives}

Because emission factors for different GHGs are not well correlated across crops and production practices, programs monitoring all three GHGs are likely to be more complex and more costly to administer than programs focussing on one GHG. For instance, a given practice such as reduced $\mathrm{N}$ fertilizer may decrease carbon sequestration while at the same time reducing emissions of $\mathrm{N}_{2} \mathrm{O}$. Consequently, as in our model, the GHG emission rate may be a non-monotonic function of $\mathrm{N}$ intensity, which complicates policy design. In addition, several studies before us have focussed on carbon sequestration, perhaps in anticipation that $\mathrm{CO}_{2}$ would be the GHG mostly likely to be regulated. It thus seems relevant to compare the social costs of second-best policies regulating a single GHG with that of 
the first best. Such second-best policies are expected to entail lower knowledge acquisition costs due to their focus on a single gas. To the extent that the relationship between single gas emissions and management practices is simpler than that involving all GHGs combined, they could also entail lower enforcement costs as the incentive schedules could perhaps be simplified.

Second-best policies relying on single gas incentives can be represented within a program similar in structure to (4), except that the emission constraint of the inner program becomes $\sum_{g \in G} \sum_{i \in I} x_{g i 1} e_{g i l}\left(\frac{x_{g i 2}}{x_{g i 1}}, \frac{x_{g i 3}}{x_{g i 1}}, T_{g i}\right) \leq \hat{E}$, where $l$ denotes the index of the GHG subject to the reduction target. ${ }^{28}$

Most studies on GHG mitigation from agriculture have focused on carbon sequestration (Pautsch et al., 2001; Antle et al., 2003), as it is arguably easier to monitor than $\mathrm{N}_{2} \mathrm{O}$ emissions (Antle and Ogle, 2012). Because $\mathrm{N}_{2} \mathrm{O}$ abatement predominates in our study, we consider second-best policies regulating either $\mathrm{CO}_{2}$ or $\mathrm{N}_{2} \mathrm{O}$ emissions. Reductions in $\mathrm{CH}_{4}$ are negligible in our cropping system under the first-best policy and thus we do not consider a $\mathrm{CH}_{4}$ reduction policy.

Figure 7 shows that regulating $\mathrm{N}_{2} \mathrm{O}$ emissions leads to lower social costs than regulating carbon sequestration for the range of abatement targets considered here. This result is not surprising given that $\mathrm{N}_{2} \mathrm{O}$ constitutes the majority of abatement under the first best. In fact, for very low abatement targets a policy focusing exclusively on $\mathrm{N}_{2} \mathrm{O}$ emissions performs almost as well as the first best, thanks to the low social costs associated with small adjustments along the $\mathrm{N}$ intensity margin. Yet, the distortions created by omitting other GHGs increase for larger abatement targets. For instance, at $\$ 20 / \mathrm{tCO}_{2}$ e regulating $\mathrm{N}_{2} \mathrm{O}$ emissions results in a $16 \%$ abatement loss relative to the first best; the social cost associated with a $1 \mathrm{MtCO}_{2} \mathrm{e}$ abatement target is $24 \%$ higher than that associated with the first-best policy.

In comparison, abatement efficiency losses associated with a policy regulating carbon sequestration amount to $21 \%$ relative to the first best at a social price of $\$ 20 / \mathrm{tCO}_{2} \mathrm{e}$. Under such a second-best policy, the social cost associated with a 1 $\mathrm{MtCO}_{2} \mathrm{e}$ abatement target increases by $37 \%$ relative to the first best.

\footnotetext{
${ }^{28}$ To make the presentation of our results clearer, we do not cumulate single GHG incentives with the spatial aggregation of emission factors. Since the previous section showed that emission factor aggregation leads to minimal abatement efficiency losses, assuming regional emission factors when investigating single GHG incentives remains relevant.
} 


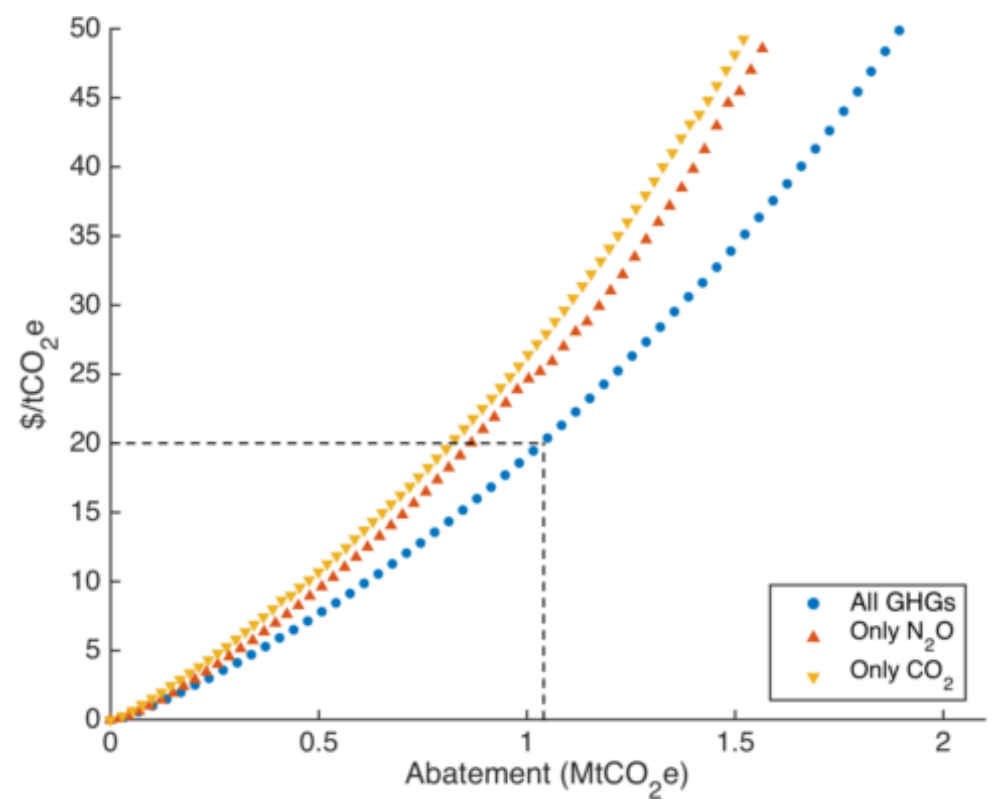

Figure 7 Marginal abatement costs under the first-best policy and second-best policies regulating carbon sequestration or $\mathrm{N}_{2} \mathrm{O}$ emissions

\subsection{Regulation of agricultural inputs}

Provided that the regulating agency has perfect knowledge of the GHG emission generation process, simultaneously monitoring the crop mix and the production practices through a practice-based incentive schedule would be equivalent to directly monitoring GHG emissions. Yet, monitoring all production practices may be technically and politically difficult, particularly because inputs would need to be regulated differently across activities and geographical regions. Such a system would create incentives to cheat through input reallocation across crops and regions, which could only be harnessed through extensive record-keeping activities. These activities would increase both the private and administrative costs of implementation. Recent work suggests that implicit transaction costs in environmental service contracts may be large and may explain the low uptake of many environmental contract schemes (Peterson et al., 2015).

Regulating inputs irrespective of activity or location within the Central Valley may be achievable at a more reasonable cost, for instance by levying a tax on $\mathrm{N}$ fertilizer or by using satellite imagery to observe crop residue cover and infer 
tillage intensity. Furthermore, the regulator may combine instruments, such as taxes on tillage and $\mathrm{N}$ fertilizer, to mitigate the distortions created by the use of a single instrument. Such policies, in addition to being less costly to enforce than activity- and region-specific incentives, would likely entail much lower knowledge acquisition costs than the first-best policy, as they would not require knowledge of the emission generation process. Here, we derive the social costs of second-best policies that regulate input use and/or tillage choice irrespective of the activity or location. We investigate water and $\mathrm{N}$ taxes, a tillage tax, and a combination of a $\mathrm{N}$ tax and a tillage tax. ${ }^{29}$

These second-best policies can again be represented within the framework of program (4), with the emission constraint of the inner program replaced, in the case of a $\mathrm{N}$ tax for instance, by the constraint $\sum_{g \in G} \sum_{i \in I} x_{g i 3} \leq \hat{X}_{3}$, where $\hat{X}_{3}$ is a $\mathrm{N}$ cap that becomes the choice variable of the outer program. ${ }^{30}$

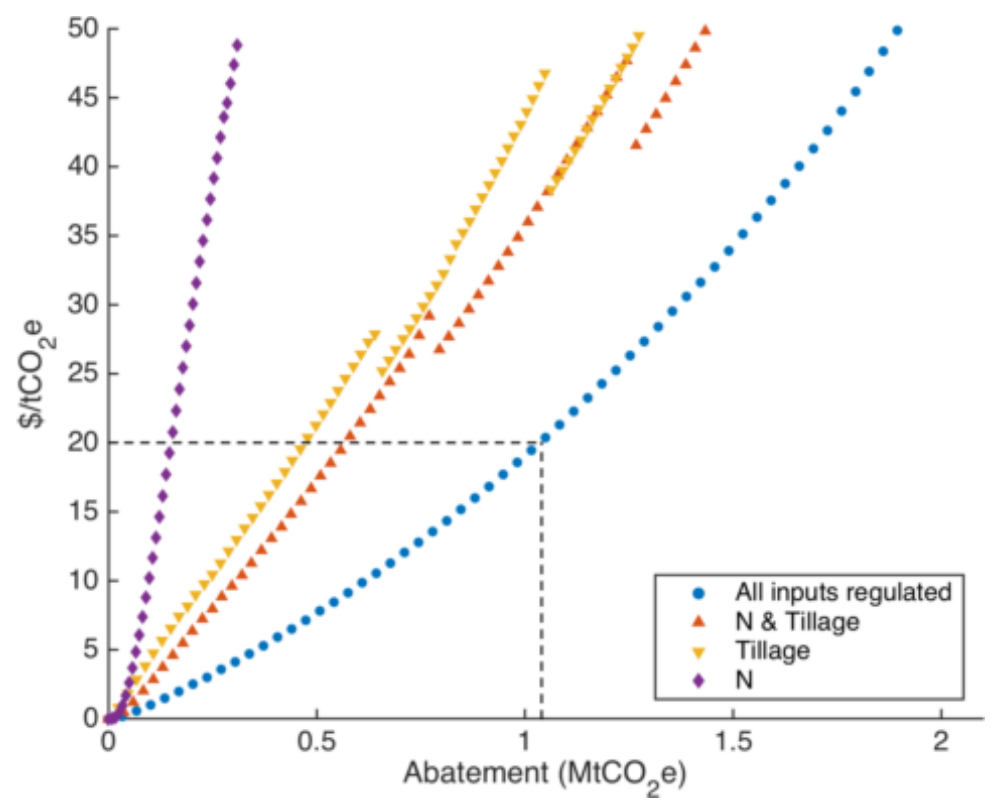

Figure 8 Marginal abatement costs under the first-best policy and second-best policies regulating tillage intensity, $\mathrm{N}$ fertilizer, or both

Regulating a single input such as $\mathrm{N}$ fertilizer, water, or tillage intensity leads

\footnotetext{
${ }^{29}$ Under the assumption that tillage intensity can be measured, a tillage tax would be a levy per unit of soil disturbance.

${ }^{30} \mathrm{~A}$ tax on tillage can be represented by the constraint $\sum_{g \in G} \sum_{i \in I} x_{g i 1} T_{g i} \leq \hat{T}$.
} 
to substantially higher social costs of GHG emission abatement than the firstbest policy, as illustrated in Figure 8. The marginal social costs associated with a water tax are higher than $\$ 230 / \mathrm{tCO}_{2}$ e for any abatement level greater than $0.5 \%$ of baseline emissions and they are not represented on the figure.

Taxing tillage intensity leads to large social costs relative to the first-best policy, particularly for very low abatement targets since such a policy fails to provide incentives to reduce $\mathrm{N}$ intensity, a socially inexpensive source of emission savings at low abatement levels. The tillage tax policy performs somewhat better for larger abatement targets, although it misses relatively low-cost abatement possibilities from changes in the crop mix. At $\$ 20 / \mathrm{tCO}_{2} \mathrm{e}$, this policy results in a $55 \%$ abatement loss relative to the first-best policy. The tillage tax required to achieve this level of abatement would translate into a cost of $\$ 43 /$ ha at baseline tillage levels. The social cost associated with a $1 \mathrm{MtCO}_{2} \mathrm{e}$ abatement target is $149 \%$ higher than that of the first-best policy.

In our model, discontinuities in the restricted marginal social cost curve arise whenever one of the choice variables hits a bound, so that adjustment along this variable in response to further increments in the abatement target is no longer possible. Two discontinuities are notable in Figure 8 for the tillage policy: at $0.63 \mathrm{MtCO}_{2} \mathrm{e}$ and at $1.05 \mathrm{MtCO}_{2} \mathrm{e}$ when the no-till technology $(T=0)$ is chosen for wheat in the SV and the SJV, respectively. Note that although the marginal social cost may not be continuous and monotonically increasing in the abatement target, the social cost always is.

The social cost of a $\mathrm{N}$ tax is generally much higher than that of a tillage tax, with the exception of extremely low abatement targets. Such targets can be achieved at low marginal social costs (less than $\$ 1 / \mathrm{tCO}_{2} \mathrm{e}$ ) because for many crops farmers can reduce $\mathrm{N}$ fertilizer use while incurring only minimal yield losses. However, the abatement supply rapidly becomes very inelastic, with an upper bound of $0.32 \mathrm{MtCO}_{2} \mathrm{e}$ for the range of social prices considered here. Because $\mathrm{N}$ intensity affects yield but tillage does not, and the correlation between GHG emissions and $\mathrm{N}$ intensity is less clear than that for tillage, at least for some crops and regions (see Figure B.1), taxing N overall entails larger social costs than taxing tillage. For instance, taxing $\mathrm{N}$ fertilizer leads to an $85 \%$ abatement loss relative to the first best at a carbon price of $\$ 20 / \mathrm{tCO}_{2} \mathrm{e}$. A tax of $\$ 0.13 / \mathrm{kg}$ of 
applied $\mathrm{N}$ is required to achieve this abatement level in our agricultural system, representing a $16 \%$ increase relative to the price of $\$ 0.82 / \mathrm{kg}$ of $\mathrm{N}$ reported in the USDA-NASS database for urea fertilizer in 2005. We cannot calculate the social cost associated with a $1 \mathrm{MtCO}_{2} \mathrm{e}$ abatement target because this target cannot be achieved within the range of social carbon prices considered.

The relatively low performance of input tax schemes can largely be explained by their failure to incentivize the correct extensive margin adjustments, which represent about one third of total abatement under the first best. For instance, under the first best, the acreage of low-emitting crops such as wheat and alfalfa increases substantially (see Figure 4), whereas it decreases for wheat and increases only moderately for alfalfa under the N tax. Similarly, the acreage of sunflower, a high-emitting crop, decreases substantially under the first best whereas it remains steady under a $\mathrm{N}$ tax. A secondary source of abatement inefficiency lies in the fact that even under the correct crop acreage allocation, a cap on input use need not allocate that input across crops so as to minimize GHG abatement costs.

Combining policy instruments mitigates some but not all of the efficiency costs associated with single tax schemes. Figure 8 shows the restricted marginal social cost of abatement under a combination of $\mathrm{N}$ and tillage taxes, where at each abatement level the optimal mix of tillage tax and $\mathrm{N}$ tax is implemented. Because this incentive scheme is more flexible than the single tax policies, the implied social cost of achieving any abatement level lies below that for the single taxes. Discontinuities in the marginal social cost curve can still be observed because of the adoption of no-till technology for wheat systems in each of the two valleys. The double-tax scheme takes advantage of the low-cost abatement generated by the $\mathrm{N}$ tax for very low abatement levels and of the incentives to reduce tillage intensity provided by the tillage tax for higher abatement levels. The social cost associated with a $1 \mathrm{MtCO}_{2} \mathrm{e}$ abatement target is $106 \%$ higher than that of the first-best policy, while this cost was $149 \%$ higher under the single tillage tax. At a social price of $\$ 20 / \mathrm{tCO}_{2} \mathrm{e}$, the double-tax scheme results in a $45 \%$ abatement loss relative to the first best, an improvement over the $55 \%$ abatement loss with the tillage tax or the $85 \%$ loss with the $\mathrm{N}$ tax. ${ }^{31}$

\footnotetext{
${ }^{31}$ The taxes required to achieve this abatement level are of $\$ 0.11 / \mathrm{kg}$ of $\mathrm{N}$ and $\$ 40 / \mathrm{ha}$ at baseline tillage levels.
} 
Admittedly, implementing an optimal mix of $\mathrm{N}$ and tillage taxes would require knowledge not only of the emission generation process, but also of the opportunity costs of management practices. A more realistic policy would thus rely on average emission rates per unit of $\mathrm{N}$ fertilizer and per unit of tillage intensity to set the ratio of $\mathrm{N}$ to tillage taxes. To investigate how much abatement efficiency would be lost by implementing this more realistic variant, we derive a region- and cropaggregated emission factor function of the form $e=\gamma_{0}+\gamma_{2} a_{2}+\gamma_{3} a_{3}+\gamma_{T} T$, and then assume that the regulator would choose pairs of tillage and nitrogen taxes $\left(\tau_{3}, \tau_{T}\right)$ such that $\frac{\tau_{3}}{\tau_{T}}=\frac{\gamma_{3}}{\gamma_{T}}$. That is, $\mathrm{N}$ fertilizer and tillage would be taxed in proportion to their average emission intensity across the entire cropping system. Such a scheme would thus require much less information than the optimal tax combination. As it turns out, the resulting curve is almost identical to the one derived under the optimal schedule of taxes. Therefore, the overwhelming majority of the welfare loss arising from using the more realistic policy comes from the inability to trigger the right set of adjustments through flat input tax rates, rather than from imperfect information.

To conclude this section, in Table 3 we summarize the GHG emissions abated at $\$ 20 / \mathrm{tCO}_{2} \mathrm{e}$ and the social costs associated with a $1 \mathrm{MtCO}_{2} \mathrm{e}$ abatement target for the first-best and second-best policies. Second-best policies using spatially aggregated emission factors perform better than policies regulating a single GHG, which themselves outperform policies regulating a single input. Regulating $\mathrm{N}$ and tillage simultaneously partly mitigates the distortions arising from the single tax schemes.

\section{$6 \quad$ Implementation costs}

Our investigation of second-best GHG mitigation schemes is predicated upon the premise that the first-best policy is either unfeasible or prohibitively expensive to implement in terms of informational, monitoring, and political costs. Here we provide a set of back-of-the-envelope calculations that show how the second-best schemes described above would fare relative to each other and relative to the first best once their monitoring costs are taken into consideration.

We assume that each policy is implemented through contracts that specify 
Table 3 GHG emissions abated in $\mathrm{MtCO}_{2} \mathrm{e} /$ year at $\$ 20 / \mathrm{tCO}_{2} \mathrm{e}$ under the first-best and second-best policies, and social costs associated with a $1 \mathrm{MtCO}_{2} \mathrm{e} /$ year abatement target

\begin{tabular}{lcccccccc}
\hline & \multicolumn{4}{c}{ Second-best policies } \\
\cline { 3 - 9 } & $\begin{array}{c}\text { First-best } \\
\text { policy }\end{array}$ & $\begin{array}{c}\text { Spatially aggr. } \\
\text { emission factors }\end{array}$ & \multicolumn{2}{c}{$\begin{array}{c}\text { Regulation of } \\
\text { a single }\end{array}$} & \multicolumn{3}{c}{$\begin{array}{c}\text { Regulation } \\
\text { of inputs }\end{array}$} \\
\cline { 3 - 9 } & & Valley & $\mathrm{CA}$ & $\mathrm{CO}_{2}$ & $\mathrm{~N}_{2} \mathrm{O}$ & Tillage & $\mathrm{N}$ & Till. \& N \\
\hline Abatement & 1.03 & 0.98 & 0.93 & 0.82 & 0.87 & 0.47 & 0.15 & 0.57 \\
Social cost & 0.42 & 0.44 & 0.45 & 0.57 & 0.52 & 1.04 & - & 0.86 \\
\hline
\end{tabular}

Note: Social costs are expressed as a percentage of baseline agricultural profit. The social cost associated with a $\mathrm{N}$ policy cannot be calculated because the $1 \mathrm{MtCO}_{2} \mathrm{e}$ abatement target cannot be achieved within the range of social carbon prices considered.

payments to be received by farmers for adopting a set of practices. Conditional on the type of policy considered (e.g., consideration of $\mathrm{CO}_{2}$ only), we assume that the payment schedule consists of discrete sets of practices and related payments that are based on the conditional emission factors associated with these practices. The construction of these schedules thus requires knowledge of the emission generation process, but not of the private opportunity costs of practice adoption. In effect, these discrete schedules are a practical way to approximate the continuous processes reflected in the abatement cost curves derived in Sections 4 and $5 .^{32}$

We mean to include both agency and farmer transactional costs in these monitoring costs, to the extent that these are borne on a yearly basis. We exclude from our analysis knowledge acquisition costs related to the development of conditional emission factors, as these costs would be borne at the outset of the program but not every year. Nonetheless, one should bear in mind that developing conditional emission factors tailored to local conditions would likely entail larger informational costs than developing spatially uniform factors. We also abstract from modeling the political costs associated with different schemes, as these are difficult to quantify. Again, these costs would likely be high for the first best as the

\footnotetext{
${ }^{32}$ The payment schedules we consider are similar in nature to the abatement action permit system advocated by Kling (2011). We prefer to describe a payment system as we are borrowing our monitoring cost from a literature on agri-environmental contracts. Also note that although we consider contracts, the $\mathrm{N}$ reduction incentive could be implemented through a direct tax on fertilizer sales, which could result in lower implementation costs as monitoring fertilizer application rates would no longer be necessary.
} 
incentive scheme could be perceived as inequitable, leading to increased lobbying and possibly legal challenges.

Our model of monitoring costs relies on three central assumptions: (i) a per hectare measure of monitoring costs associated with the first-best policy, (ii) a set of adjustment factors to account for the reduced burden of implementing secondbest policies, and (iii) a set of rules to infer the number of hectares enrolled under a given scheme. Before presenting results from our monitoring cost calculations, we explain each assumption in detail.

\subsection{Monitoring cost of the first-best policy}

There is a scant literature on the implementation costs of environmental contractual programs in U.S. agriculture. The recent study by Antle et al. (2007b) on carbon sequestration through fallow reduction and conservation tillage adoption in the central U.S. acknowledges this gap and proposes a measure of transactional costs per hectare of contracted farmland of $\$ 5 /$ acre $(\$ 12.4 /$ ha). This measure is meant to include transaction costs associated with geographically differentiated carbon contracts, including physical measurements of carbon sequestered in soils through sampling, and therefore we view it as conservative since our contractual framework relies on practice adoption rather than physical measurements. ${ }^{33} \mathrm{We}$ assume that this cost applies to the first-best scheme.

\subsection{Monitoring cost of second-best policies}

The monitoring cost of second-best policies is deduced from that of the first best by applying adjustment factors based on the complexity of the payment schedule needed to incentivize abatement under each scheme. The general formula for the cost per hectare is $C^{\text {second best }}=(1-\kappa) \times C^{\text {first best }}+\kappa \theta^{\text {second best }} \times C^{\text {first best }}$, where $C$ is the monitoring cost, $1-\kappa$ represents the share of per hectare costs that is independent of schedule complexity, and $\theta^{\text {second best }} \leq 1$ is the policy-specific attenuation factor that reflects the complexity of the payment schedule relative

\footnotetext{
${ }^{33}$ Antle et al. (2003) provide measures of these physical measurements for grain-producing regions in Montana. Depending on location and sampling frequency, their estimates vary between $\$ 0.15 /$ ha and $\$ 3.40 /$ ha.
} 
to the first best.

We assume that $\kappa \in\{0.50,0.75\}$. We then assume that the farming practices are discretized as follows under the first-best policy: the crop is chosen among the 7 alternatives modeled in our system; the tillage intensity is chosen among the 5 lower values described in Table A.1; the water intensity is allowed to take on 4 values; and the $\mathrm{N}$ fertilizer intensity is allowed to take on 4 values. Adjusting for the fact that alfalfa is not tilled or fertilized, and allowing each of the 27 modeled regions to have their own set of payments based on local biophysical conditions, the maximum number of practice combinations is 13,068 .

Because policies that incentivize only one of the three GHGs involve the same number of margins, here we assume that their monitoring cost is the same as that of the first best. Policies relying on spatially aggregated emission factors involve lower implementation costs as the number of entries in the payment schedule drops to 968 (valley-specific factors) and 484 (state-level factors), leading to attenuation factors $\theta^{\text {second best }}$ of $\frac{968}{13,068}$ and $\frac{484}{13,068}$, respectively. Policies incentivizing the use of an input irrespective of location or crop have the lowest implementation costs as the number of entries is very small relative to the other policies.

\subsection{Hectares enrolled in a program}

For a given policy, we deduce the number of hectares enrolled from the regionalized bio-economic model used in Sections 4 and 5. To that effect, we develop a set of rules to map predicted changes in acreage and management practices at the regional level into enrollment. The underlying idea is that the larger the predicted changes in management practices relative to the baseline, the more hectares have been enrolled. We focus on the three main margins of adjustment relevant to our model: changes in crop allocation, changes in tillage intensity conditional on crop choice, and changes in $\mathrm{N}$ fertilizer intensity conditional on crop choice. For the sake of simplicity, we assume independence across changes in these margins, that is, we assume that hectares enrolled for crop changes are different than those enrolled for changes in input intensity. As a result, our procedure likely overstates the number of hectares enrolled as farmers would likely change more than a single margin on a given plot of land. 


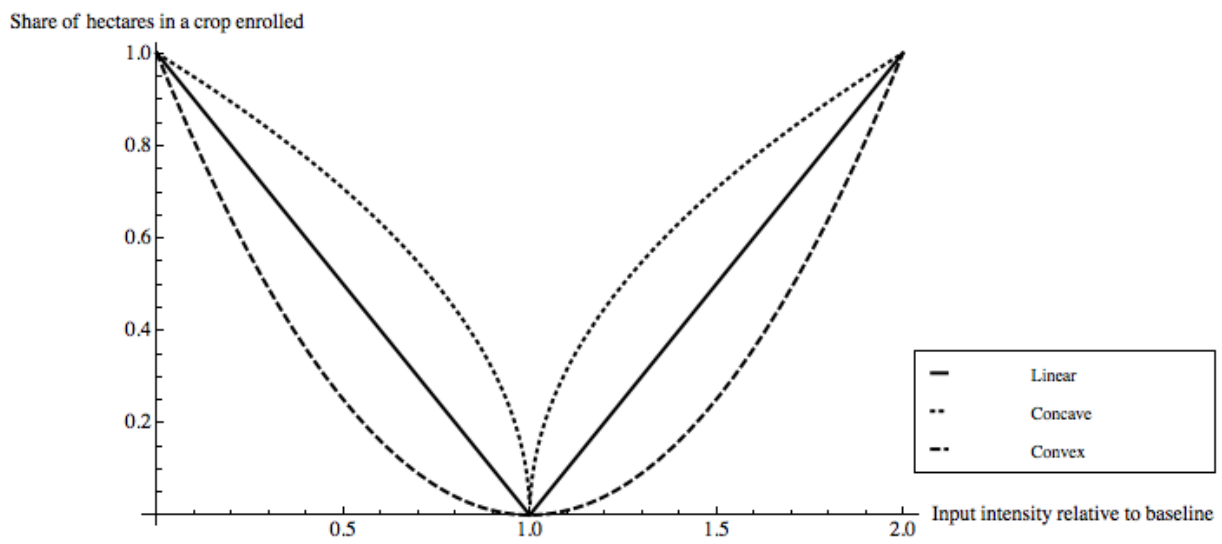

Figure 9 Contribution of intensive margin changes to acreage enrollment under alternative rules

To infer hectares enrolled through crop re-allocation, we simply add up the increase in acreage for crops that expand (by construction, it is equal to the sum of the acreage declines for crops that contract minus any non-cropped acreage). To infer hectares enrolled through intensive margin adjustments, we assume that if, conditional on crop choice, input intensity falls to zero (no fertilizer or no till), then all hectares in that crop under the policy have been enrolled. Symmetrically, we assume that if input intensity doubles relative to the baseline, then all hectares in that crop under the policy have been enrolled. ${ }^{34}$ We then make assumptions regarding the share of hectares in a given crop that have been enrolled if we observe intermediate changes in input intensity. We investigate linear, concave, and convex interpolations. In the linear interpolation, the share of hectares enrolled is increasing linearly with the intensity of the change in input intensity. We use a square root (resp. quadratic) interpolation to mimic the case of a concave (resp. convex) enrollment relationship. Figure 9 represents these three interpolation rules graphically. The concave interpolation predicts a higher share of enrollment

\footnotetext{
${ }^{34}$ This second assumption is only used for $\mathrm{N}$ fertilizer as there is no instance of an increase in tillage in our simulations.
} 
than the other two interpolations, resulting in a larger monitoring cost estimate for any given policy.

\subsection{Monitoring cost estimates}

We set the abatement target at an exogenous value of $1 \mathrm{MtCO}_{2} \mathrm{e}$ per year. We value these emission reductions at a unit price of $\$ 20 / \mathrm{tCO}_{2} \mathrm{e}$. Table 4 reports the costs and benefits net of opportunity and monitoring costs for the first-best and second-best policies. We do not report values for the $\mathrm{N}$ fertilizer incentive as the abatement target is not reachable with this policy.

Table 4 shows that, ignoring knowledge acquisition and political costs, most of the policies considered generally exhibit a positive net benefit, with the exception of the single tillage incentive. Despite the reduced monitoring costs associated with a simple input incentive, the abatement efficiency loss is large enough to make this policy welfare-reducing. As expected from the abatement efficiency analysis, schemes that reward practices based on spatially uniform emission factors perform favorably relative to the first best, particularly under assumptions that lead to higher enrollment (linear and concave interpolations). Single GHG schemes perform poorly relative to the first best as they entail comparable (or, in the case of $\mathrm{CO}_{2}$, larger) monitoring costs and a sizable abatement efficiency loss. This finding is important in light of the fact that several proposals for GHG mitigation from the agricultural sector have focussed on carbon sequestration while ignoring emissions of $\mathrm{N}_{2} \mathrm{O} .{ }^{35}$ Finally, our analysis suggests that a policy incentivizing tillage and fertilizer reductions irrespective of location or crop, even when generating positive net benefits, remains dominated by policies that simultaneously incentivize input use and crop choice. This finding holds even if one assumes that the input incentive policy can be implemented free of monitoring costs (column $B-O C$ in Table 4).

\footnotetext{
${ }^{35}$ See, for instance, the $4 / 1000$ initiative launched at COP 21 in 2015 to increase global soil carbon stocks (http://newsroom.unfccc.int/lpaa/agriculture/ join-the-41000-initiative-soils-for-food-security-and-climate/) or the healthy soils initiative of the California Department of Food and Agriculture (https://www.cdfa. ca.gov/oefi/healthysoils/).
} 
Table 4 Net benefits of policies abating $1 \mathrm{MtCO}_{2} \mathrm{e} /$ year

\begin{tabular}{|c|c|c|c|c|c|}
\hline & $\begin{array}{c}B-O C \\
\mathrm{M} \$\end{array}$ & $\theta^{\text {policy }}$ & $\begin{array}{c}A \\
1,000 \text { ha }\end{array}$ & $\begin{array}{c}B-O C-M C \\
\kappa=0.50 \\
\mathrm{M} \$\end{array}$ & $\begin{array}{c}B-O C-M C \\
\kappa=0.75 \\
\mathrm{M} \$\end{array}$ \\
\hline \multicolumn{6}{|l|}{ Linear interpolation } \\
\hline First best & 11.48 & 1 & 289 & 7.91 & 7.91 \\
\hline Valley-level factors & 10.96 & 0.074 & 305 & 8.94 & 9.81 \\
\hline CA-level factors & 10.83 & 0.037 & 301 & 8.90 & 9.79 \\
\hline $\mathrm{CO}_{2}$ only & 8.33 & 1 & 337 & 4.17 & 4.17 \\
\hline $\mathrm{N}_{2} \mathrm{O}$ only & 9.41 & 1 & 254 & 6.27 & 6.27 \\
\hline Tillage & -1.24 & $3.83 \mathrm{e}-04$ & 413 & -3.80 & -2.52 \\
\hline Tillage \& N & 2.49 & $1.53 \mathrm{e}-03$ & 371 & 0.19 & 1.34 \\
\hline \multicolumn{6}{|l|}{ Concave interpolation } \\
\hline First best & 11.48 & 1 & 666 & 3.25 & 3.25 \\
\hline Valley-level factors & 10.96 & 0.074 & 691 & 6.37 & 8.35 \\
\hline CA-level factors & 10.83 & 0.037 & 698 & 6.35 & 8.43 \\
\hline $\mathrm{CO}_{2}$ only & 8.33 & 1 & 707 & -0.41 & -0.41 \\
\hline $\mathrm{N}_{2} \mathrm{O}$ only & 9.41 & 1 & 606 & 1.92 & 1.92 \\
\hline Tillage & -1.24 & $3.83 \mathrm{e}-04$ & 735 & -5.78 & -3.52 \\
\hline Tillage \& N & 2.49 & $1.53 \mathrm{e}-03$ & 693 & -1.80 & 0.33 \\
\hline \multicolumn{6}{|l|}{ Convex interpolation } \\
\hline First best & 11.48 & 1 & 95 & 10.31 & 10.31 \\
\hline Valley-level factors & 10.96 & 0.074 & 102 & 10.28 & 10.57 \\
\hline CA-level factors & 10.83 & 0.037 & 98 & 10.20 & 10.49 \\
\hline $\mathrm{CO}_{2}$ only & 8.33 & 1 & 149 & 6.49 & 6.49 \\
\hline $\mathrm{N}_{2} \mathrm{O}$ only & 9.41 & 1 & 74 & 8.50 & 8.50 \\
\hline Tillage & -1.24 & $3.83 \mathrm{e}-04$ & 200 & -2.48 & -1.86 \\
\hline Tillage \& N & 2.49 & $1.53 \mathrm{e}-03$ & 156 & 1.52 & 2.00 \\
\hline
\end{tabular}

Note: $B$ : abatement benefit. Abatement is valued at $\$ 20 / \mathrm{tCO}_{2} \mathrm{e} . O C$ : private opportunity cost. $\theta^{\text {policy }}$ : relative size of payment schedule. A: acreage enrollment. $M C$ : total monitoring cost. $\kappa$ : share of monitoring cost dependent on payment schedule size. Net benefits are computed net of opportunity and monitoring costs but do not account for informational and political costs. 


\section{Conclusion}

This study examines the social costs of agricultural GHG mitigation policies. Ignoring implementation costs, a first-best policy minimizes the social opportunity cost of achieving a given GHG abatement target. However, its implementation may be infeasible or costly in terms of knowledge acquisition, monitoring, and political costs. We thus investigate the abatement efficiency costs of second-best policies that may be easier and administratively less costly to implement.

Because GHG emissions depend on multiple adjustment margins, a detailed representation of agricultural production is justified when analyzing the response of agricultural systems to GHG reduction incentives. We calibrate a regionalized model of California field crop agriculture that captures changes in crop acreage and water, $\mathrm{N}$ fertilizer, and tillage intensities to simulate the social opportunity cost of GHG emissions abatement under various policy schemes. Our analysis brings two main contributions to the debate regarding agriculture's role in GHG mitigation efforts.

First, we find that an abatement of $1.03 \mathrm{MtCO}_{2}$ e per year or $30 \%$ of baseline emissions could be obtained from our agricultural system under the first-best policy at the $\$ 20 / \mathrm{tCO}_{2}$ e price predicted by CARB for 2020. According to CARB, agriculture contributed about $37.9 \mathrm{MtCO}_{2} \mathrm{e}$ in $\mathrm{GHG}$ emissions in California in 2012, representing 8.3\% of total GHG emissions (CARB, 2014a). Among these, $23.2 \%$ or $8.8 \mathrm{MtCO}_{2} \mathrm{e}$ are attributed to agricultural soil management, the category under which our agricultural system falls. Our abatement figure therefore suggests that crop agriculture could significantly reduce its GHG emissions and, provided that emission reductions can be incentivized at reasonably low transactional costs, contribute to California's GHG reduction targets. ${ }^{36}$

How is this GHG abatement achieved in our cropping system? In the firstbest allocation, small abatement levels mostly arise from reductions in $\mathrm{N}$ fertilizer intensity obtained at very low marginal social costs. More ambitious abatement targets are then achieved largely through changes in the crop mix towards low-

\footnotetext{
${ }^{36}$ According to a CARB's 2010 analysis, reduction of an estimated $80 \mathrm{MtCO}_{2} \mathrm{e}$ is necessary to reduce statewide emissions to the AB 32 target of $427 \mathrm{MtCO}_{2} \mathrm{e}$ by 2020 (CARB, 2010b). Several of the measures pertaining to capped sectors described in this analysis amount to emission reductions of the same order of magnitude as our estimate for field crop agriculture.
} 
emitting and carbon-sequestering crops and through shifts towards lower-intensity tillage technologies. Overall, most of the GHG abatement from our agricultural system arises from reductions in $\mathrm{N}_{2} \mathrm{O}$ emissions, followed by increases in carbon sequestration. The abatement supply appears to be inelastic, with a supply elasticity of 0.74 . However, at high enough prices it could be less inelastic than the supply from other sectors (Bailey et al., 2013), which implies that inclusion of agriculture into GHG mitigation efforts, for instance through agricultural offsets, could bring some element of stability to carbon allowance prices.

Second, we find that second-best policies that likely entail reduced implementation costs compared to the first best may provide cost-effective abatement options. Specifically, our findings suggest that policies that incentivize GHG emission mitigation by relying on spatially aggregated emission factors entail very small abatement efficiency losses and may therefore represent a practical alternative to a first-best policy. Policies targeting a single GHG such as $\mathrm{N}_{2} \mathrm{O}$ or $\mathrm{CO}_{2}$ lead to moderate abatement efficiency losses. Because their monitoring costs would be comparable to those of the first best, they do not appear to be advisable. At the very least, this finding suggests that policy makers should consider all relevant GHG when designing incentive programs as emissions are not necessarily well correlated among GHGs. Single taxes on irrigation water, N fertilizer, or tillage intensity, despite their apparent simplicity, appear to be very poor GHG mitigation instruments relative to the other instruments analyzed here. A mixed policy simultaneously regulating $\mathrm{N}$ and tillage is found to achieve $55 \%$ of the first-best abatement at a social price of $\$ 20 / \mathrm{tCO}_{2} \mathrm{e}$. If, for reasons not addressed in this paper, input incentives were the sole option to bring crop agriculture into GHG mitigation efforts, a combination of input incentives might still be justified on welfare grounds. However, in our model this conclusion remains sensitive to assumptions regarding the number of hectares that would be enrolled.

An important limitation of this study is that it only captures mitigation opportunities from a subset of California crops and a subset of practices that may be relevant to GHG emissions. As such, in the absence of high transaction costs the mitigation results presented here should be interpreted as a lower bound to achievable emission reductions from California crops. While the scope of our model was dictated by the joint availability of spatially explicit biophysical and 
economic information at the time the study was conducted, we note that additional activities (e.g., rice cultivation), additional inputs (e.g., organic fertilizer), as well as alternative management technologies such as nitrification inhibitors or the use of cover crops could potentially be brought into our modeling framework to refine our abatement cost estimates.

\section{References}

Adams, R. M., Adams, D. M., Callaway, J., Chang, C.-C., and McCarl, B. A. (1993). Sequestering carbon on agricultural land: social cost and impacts on timber markets. Contemporary Economic Policy, 11(1):76-87.

Antle, J. M., Capalbo, S. M., Mooney, S., Elliott, E., and Paustian, K. (2003). Spatial heterogeneity, contract design, and the efficiency of carbon sequestration policies for agriculture. Journal of Environmental Economics and Management, 46:231-250.

Antle, J. M., Capalbo, S. M., Paustian, K., and Ali, M. K. (2007a). Estimating the economic potential for agricultural soil carbon sequestration in the Central United States using an aggregate econometric-process model. Climatic Change, 80:145-171.

Antle, J. M., Capalbo, S. M., Paustian, K., and Ali, M. K. (2007b). Estimating the economic potential for agricultural soil carbon sequestration in the central United States using an aggregate econometric-process model. Climatic Change, 80:145-171.

Antle, J. M. and Ogle, S. M. (2012). Influence of soil C, $\mathrm{N}_{2} \mathrm{O}$ and fuel use on GHG mitigation with no-till adoption. Climatic Change, 111(3-4):609-625.

Auffhammer, M. and Kellogg, R. (2011). Clearing the air? The effects of gasoline content regulation on air quality. The American Economic Review, 101(6):2687-2722.

Bailey, E. M., Borenstein, S., Bushnell, J., Wolak, F. A., and Zaragoza-Watkins, M. (2013). Forecasting supply and demand's balance in California's greenhouse gas cap and trade market. Research performed under a CARB contract.

Burtraw, D. (2013). Informational and oversight hearing of the California Senate Select Committee on climate change and AB 32 implementation. Congressional testimony, Resources for the Future, Washington. 
Burtraw, D., McLaughlin, D., and Szambelan, S. J. (2012). California's new gold: A primer on the use of allowance value created under the $\mathrm{CO}_{2}$ cap-and-trade program. Discussion Paper 12-23, Resources for the Future, Washington, D.C.

Bushnell, J., Chen, Y., and Zaragoza-Watkins, M. (2014). Downstream regulation of $\mathrm{CO}_{2}$ emissions in California's electricity sector. Energy Policy, 64:313-323.

Bushnell, J. B., Chong, H., and Mansur, E. T. (2013). Profiting from regulation: Evidence from the European carbon market. American Economic Journal: Economic Policy, 5(4):78-106.

Calzadilla, A., Rehdanz, K., and Tol, R. S. J. (2011). The GTAP-W model: Accounting for water use in agriculture. Technical report, Kiel Institute for the World Economy. Kiel Working Papers, No. 1745.

CARB (2010a). Greenhouse gas reductions from ongoing, adopted and foreseeable Scoping Plan Measures. Technical report, California Air Resources Board. Accessed August 2014 at http://www.arb.ca.gov/cc/inventory/ data/tables/reductions_from_scoping_plan_measures_2010-10-28.pdf.

CARB (2010b). Status of Scoping Plan Recommended Measures. Technical report, California Air Resources Board. Accessed August 2014 at http://www.arb.ca.gov/cc/scopingplan/sp_measures_implementation_ timeline.pdf.

CARB (2010c). Updated economic analysis of California's Climate Change Scoping Plan. Technical report, California Air Resources Board.

CARB (2014a). California greenhouse gas emission inventory: 2000-2012. Technical report, California Air Resources Board. 2014 edition.

CARB (2014b). First Update to the Climate Change Scoping Plan, Building on the Framework. Technical report, California Air Resources Board.

CARB (2014c). Potential new compliance offset protocol rice cultivation projects. Technical report, California Air Resources Board. Accessed January 2015 at http://www.arb.ca.gov/cc/capandtrade/protocols/riceprotocol.htm.

Caron, J., Rausch, S., and Winchester, N. (2015). Leakage from sub-national climate policy: The case of California's cap-and-trade program. The Energy Journal, 36(2):167-190.

Carter, C. A. (2006). Economics of the California processing tomato market. Agricultural and Resource Economics Update, 10(2):5-8. 
Choi, S.-W. and Sohngen, B. (2010). The optimal choice of residue management, crop rotations, and cost of carbon sequestration: Empirical results in the Midwest US. Climatic Change, 99(1-2):279-294.

Costinot, A., Donaldson, D., and Smith, C. (2016). Evolving comparative advantage and the impact of climate change in agricultural markets: Evidence from 1.7 million fields around the world. Journal of Political Economy, 124(1):205248.

Davis, L. W. (2008). The effect of driving restrictions on air quality in Mexico City. Journal of Political Economy, 116(1):38-81.

De Cara, S., Houzé, M., and Jayet, P.-A. (2005). Methane and nitrous oxide emissions from agriculture in the EU: A spatial assessment of sources and abatement costs. Environmental and Resource Economics, 32(4):551-583.

De Cara, S. and Jayet, P.-A. (2000). Emissions of greenhouse gases from agriculture: the heterogeneity of abatement costs in France. European Review of Agricultural Economics, 27(3):281-303.

De Gryze, S., Lee, J., Ogle, S. M., Paustian, K., and Six, J. (2011). Assessing the potential for greenhouse gas mitigation in intensively managed annual cropping systems at the regional scale. Agriculture, Ecosystems and Environment, 144:150-158.

De Gryze, S., Wolf, A., Kaffka, S., Mitchell, J., Rolston, D., Temple, S., Lee, J., and Six, J. (2010). Simulating greenhouse gas budgets of four California cropping systems under conventional and alternative management. Ecological Applications, 20(7):1805-19.

Del Grosso, S. J., Parton, W. J., Mosier, A. R., Hartman, M. D., Brenner, J., Ojima, D. S., and Schimel, D. S. (2001). Simulated interaction of carbon dynamics and nitrogen trace gas fluxes using the DAYCENT model. In Schaffer, M., Ma, L., and Hansen, S., editors, Modeling carbon and nitrogen dynamics for soil management, pages 303-332. CRC Press, Boca Raton, FL.

Del Grosso, S. J., Parton, W. J., Mosier, A. R., Ojima, D. S., Kulmala, A. E., and Phongpan, S. (2000). General model for $\mathrm{N}_{2} \mathrm{O}$ and $\mathrm{N}_{2}$ gas emissions from soils due to denitrification. Global Biogeochemical Cycles, 14:1045-1060.

Durandeau, S., Gabrielle, B., Godard, C., Jayet, P. A., and Le Bas, C. (2010). Coupling biophysical and micro-economic models to assess the effect of mitigation measures on greenhouse gas emissions from agriculture. Climatic Change, $98(1-2): 51-73$. 
Environmental Protection Agency (2015). Sources of greenhouse gas emissions, agriculture sector emissions. www3.epa.gov/climatechange/ghgemissions/ sources/agriculture.html. Accessed January 14, 2016.

Feng, H., Kurkalova, L. A., Kling, C. L., and Gassman, P. W. (2006). Environmental conservation in agriculture: Land retirement vs. changing practices on working land. Journal of Environmental Economics and Management, 52:600614.

Fowlie, M., Reguant, M., and Ryan, S. P. (2016). Market-based emissions regulation and industry dynamics. Journal of Political Economy, 124(1):249-302.

Fullerton, D. and Gan, L. (2005). Cost-effective policies to reduce vehicle emissions. The American Economic Review, 95(2):300-304.

Fullerton, D. and West, S. E. (2002). Can taxes on cars and on gasoline mimic an unavailable tax on emissions? Journal of Environmental Economics and Management, 43(1):135-157.

Garnache, C. and Mérel, P. R. (2015). What can acreage allocations say about crop supply elasticities? A convex programming approach to supply response disaggregation. Journal of Agricultural Economics, 66(1):236-256.

Garnache, C. and Mérel, P. R. (2016). On the derivation of second-best marginal abatement cost curves. Working Paper.

Garnache, C., Mérel, P. R., Howitt, R. E., and Lee, J. (2016). Calibration of shadow values in constrained optimisation models of agricultural supply. Working Paper.

Godard, C., Roger-Estrade, J., Jayet, P.-A., Brisson, N., and Le Bas, C. (2008). Use of available information at a European level to construct crop nitrogen response curves for the regions of the EU. Agricultural Systems, 97:68-82.

Heckelei, T., Britz, W., and Zhang, Y. (2012). Positive mathematical programming approaches - Recent developments in literature and applied modelling. Bio-based and Applied Economics, 1(1):109-124.

Hertel, T. W., Stiegert, K., and Vroomen, H. (1996). Nitrogen-land substitution in corn production: A reconciliation of aggregate and firm-level evidence. American Journal of Agricultural Economics, 78(1):30-40.

Horowitz, J. and Gottlieb, J. (2010). The role of agriculture in reducing greenhouse gas emissions. Economic brief 15, United States Department of Agriculture, Economic Research Service. 
Howitt, R. E. (1995a). A calibration method for agricultural economic production models. Journal of Agricultural Economics, 46(2):147-159.

Howitt, R. E. (1995b). Positive mathematical programming. American Journal of Agricultural Economics, 77(2):329-342.

Howitt, R. E., Medellín-Azuara, J., MacEwan, D., and Lund, J. R. (2012). Calibrating disaggregate economic models of agricultural production and water management. Environmental Modelling and Software, 38:244-258.

Innes, R. (1996). Regulating automobile pollution under certainty, competition, and imperfect information. Journal of Environmental Economics and Management, 31(2):219-239.

Jenkins, M. W., Draper, A. J., Lund, J. R., Howitt, R. E., Tanaka, S. K., Ritzema, R. S., Marques, G. F., Msangi, S. M., Newlin, B. D., Van Lienden, B. J., Davis, M. D., and Ward, K. B. (2001). Improving California water management: Optimizing value and flexibility. Technical Report 01-1, Center for Environmental and Water Resources Engineering, University of California., Sacramento, CA.

Kling, C. L. (2011). Economic incentives to improve water quality in agricultural landscapes: Some new variations on old ideas. American Journal of Agricultural Economics, 93(2):297-309.

Kurkalova, L. A., Kling, C. L., and Zhao, J. (2004). Multiple benefits of carbonfriendly agricultural practices: Empirical assessment of conservation tillage. Environmental Management, 33(4):519-527.

Lal, R., Follett, R., and Kimble, J. (2003). Achieving soil carbon sequestration in the U.S.: A challenge to the policy makers. Soil Science, 168(12):827-845.

Lal, R., Kimble, L., Follett, R., and Cole, C. (1998). The Potential of U.S. Cropland to Sequester $C$ and Mitigate the Greenhouse Effect. Ann Arbor Press, Chelsea, MI.

Larson, D. M., Helfand, G. E., and House, B. W. (1996). Second-best tax policies to reduce nonpoint source pollution. American Journal of Agricultural Economics, 78(4):1108-1117.

Lubowski, R. N., Plantinga, A. J., and Stavins, R. N. (2006). Land-use change and carbon sinks: Econometric estimation of the carbon sequestration supply function. Journal of Environmental Economics and Management, 51(2):135152. 
McCarl, B. A. and Schneider, U. A. (2001). Greenhouse gas mitigation in U.S. agriculture and forestry. Science, 294(5551):2481-2482.

Mérel, P. and Howitt, R. (2014). Theory and application of positive mathematical programming in agriculture and the environment. Annual Review of Resource Economics, 6(1):451-470.

Mérel, P. R., Simon, L. K., and Yi, F. (2011). A fully calibrated generalized constant-elasticity-of-substitution programming model of agricultural supply. American Journal of Agricultural Economics, 93:936-948.

Mérel, P. R., Yi, F., Lee, J., and Six, J. (2014). A regional bio-economic model of nitrogen use in cropping. American Journal of Agricultural Economics, 96(1):67-91.

Mitchell, J., Klonsky, K., Shrestha, A., Fry, R., DuSault, A., and Beyer, J. Harben, R. (2007). Adoption of conservation tillage in California: current status and future perspectives. Australian Journal of Experimental Agriculture, 47(12):1383-1388.

Mitchell, J., Pettygrove, G., and Upadhyaya, S. (2009). Classification of conservation tillage practices in California irrigated row crop systems. Technical Report 8364, UC ANR, Oakland, CA.

Neufeldt, H., Schäfer, M., Angenendt, E., Li, C., Kaltschmitt, M., and Zeddies, J. (2006). Disaggregated greenhouse gas emission inventories from agriculture via a coupled economic-ecosystem model. Agriculture, Ecosystems $\mathscr{E}$ Environment, $112(2-3): 233-240$.

Newell, R. G. and Stavins, R. N. (2000). Climate change and forest sinks: Factors affecting the costs of carbon sequestration. Journal of Environmental Economics and Management, 40(3):211-235.

Ogle, S., Swan, A., and Paustian, K. (2012). No-till management impacts on crop productivity, carbon input and soil carbon sequestration. Agriculture, Ecosystems and Environment, 149:37-49.

Parton, W. J., Mosier, A. R., Ojima, D. S., Valentine, D. W., Schimel, D. S., Weier, K., and Kulmala, A. E. (1996). Generalized model for $\mathrm{N}_{2}$ and $\mathrm{N}_{2} \mathrm{O}$ production from nitrification and denitrification. Global Biogeochemical Cycles, 10:401-412.

Parton, W. J., Schimel, D. S., Cole, C. V., and Ojima, D. S. (1987). Analysis of factors controlling soil organic matter levels in great plains grasslands. Soil Science Society of America Journal, 51:1173-1179. 
Pautsch, G., Kurkalova, L., Babcock, B. A., and Kling, C. (2001). The efficiency of sequestering carbon in agricultural soils. Contemporary Economic Policy, 19(2):123-134.

Peterson, J. M., Smith, C. M., Leatherman, J. C., Hendricks, N. P., and Fox, J. A. (2015). Transaction costs in payment for environmental service contracts. American Journal of Agricultural Economics, 97(1):219-238.

Pittelkow, C. M., Liang, X., Linquist, B. A., van Groenigen, K. J., Lee, J., Lundy, M. E., van Gestel, N., Six, J., Venterea, R. T., and van Kessel, C. (2014). Productivity limits and potentials of the principles of conservation agriculture. Nature. Available at doi:10.1038/nature13809.

Plantinga, A. J., Mauldin, T., and Miller, D. J. (1999). An econometric analysis of the costs of sequestering carbon in forests. American Journal of Agricultural Economics, 81(4):812-824.

Powlson, D. S., Stirling, C. M., Jat, M. L., Gerard, B. G., Palm, C. A., Sanchez, P. A., and Cassman, K. G. (2014). Limited potential of no-till agriculture for climate change mitigation. Nature Climate Change, 4:678-683.

Robertson, G. P., Gross, K. L., Hamilton, S. K., Landis, D. A., Schmidt, T. M., Snapp, S. S., and Swinton, S. M. (2014). Farming for ecosystem services: An ecological approach to production agriculture. BioScience, 64(5):404-415.

Rosas, F., Babcock, B. A., and Hayes, D. J. (2011). A nonlinear offset program to reduce nitrous oxide emissions induced by excessive nitrogen application. Working Paper 11-WP 521, Center for Agricultural and Rural Development.

Schneider, U. A. and McCarl, B. A. (2003). Economic potential of biomass based fuels for greenhouse gas emission mitigation. Environmental and Resource Economics, 24:291-312.

Schneider, U. A., McCarl, B. A., and Schmid, E. (2007). Agricultural sector analysis on greenhouse gas mitigation in US agriculture and forestry. Agricultural Systems, 94(2):128-140.

Six, J., Ogle, S. M., Jay breidt, F., Conant, R. T., Mosier, A. R., and Paustian, K. (2004). The potential to mitigate global warming with no-tillage management is only realized when practised in the long term. Global Change Biology, 10(2):155-160.

Snyder, C., Bruulsema, T., Jensen, T., and Fixen, P. (2009). Review of greenhouse gas emissions from crop production systems and fertilizer management effects. Agriculture, Ecosystems \&6 Environment, 133:247-266. 
Springborn, M., Yeo, B.-L., Lee, J., and Six, J. (2013). Crediting uncertain ecosystem services in a market. Journal of Environmental Economics and Management, 66(3):554-572.

Stavins, R. N. (1999). The costs of carbon sequestration: A revealed-preference approach. American Economic Review, 89(4):994-1009.

UCCE (2007). Agricultural cost and return studies. Technical report, University of California Cooperative Extension, Davis, California. http://coststudies.ucdavis.edu/.

UNFCCC (2010). Report of the Conference of the Parties on its fifteenth session, held in Copenhagen from 7 to 19 December 2009. Technical Report FCCC/CP/2009/11/Add.1, United Nations Framework Convention on Climate Change.

UNFCCC (2015). Adoption of the Paris Agreement. Technical Report FCCC/CP/2015/L.9/Rev.1, United Nations Framework Convention on Climate Change. Conference of the Parties Twenty-first session, Paris, 30 November to 11 December 2015.

van Kessel, C., Venterea, R., Six, J., Adviento-Borbe, M. A., Linquist, B., and van Groenigen, K. J. (2013). Climate, duration, and N placement determine $\mathrm{N}_{2} \mathrm{O}$ emissions in reduced tillage systems: A meta-analysis. Global Change Biology, 19:33-44.

West, T. O. and Six, J. (2007). Considering the influence of sequestration duration and carbon saturation. Climatic Change, 80(25-41).

\section{Appendices}

\section{A Tillage index}

The tillage index lies between zero and one and measures the relative degree of soil disturbance caused by tillage practices. Soil disturbance depends on the type of equipment used on the field and the frequency of its use. The index is used in our study to modulate the GHG emission factors because soil disturbance induced by different tillage practices affects soil carbon and nitrogen emissions 
(De Gryze et al., 2011). A tillage index $T=0$ describes no-till systems (low soil disturbance) and an index $T=1$ represents conventional tillage systems (high soil disturbance). Table A.1 describes the six tillage practices identified in California and their associated tillage index (Mitchell et al., 2009).

Table A.1 Characteristics of the six tillage practices identified in California

\begin{tabular}{llccc}
\hline Practice & Description & $\begin{array}{c}\text { Residue } \\
\text { cover after } \\
\text { planting }\end{array}$ & $\begin{array}{c}\text { Chisel, } \\
\text { rip or } \\
\text { subsoiling }\end{array}$ & $\begin{array}{c}\text { Tillage } \\
\text { index }\end{array}$ \\
\hline Conventional tillage (K-CT) & high soil disturbance & $0 \%$ & yes & 1 \\
CA conv. tillage (CA-CT) & medium soil disturbance & $0 \%$ & yes & 0.91 \\
Reduced tillage (RT) & tractor passes reduced by 25\% & $15-30 \%$ & no & 0.64 \\
Mulch tillage (M) & tractor passes reduced by $75 \%$ & $\geq 33 \%$ & no & 0.54 \\
Strip tillage (S) & only seed row is tilled & $\geq 30 \%$ & no & 0.41 \\
No-till (NT) & disturbance only at planting & $\geq 30 \%$ & no & 0 \\
\hline
\end{tabular}

Neither the biogeochemical model DAYCENT or the agronomic literature report a clear effect of reduced tillage technology on yield in California for the crops considered in this study (van Kessel et al., 2013; Pittelkow et al., 2014). Therefore, we assume that the choice of tillage technology affects per hectare operating costs but does not affect yield.

\section{B Conditional yields and emission factors in DAY- CENT}

\section{B.1 Overview}

The derivation of crop yield elasticities with respect to input intensities and of conditional GHG emission factors relies on the biogeochemical model DAYCENT, the daily time step-version of the well-known Century model (Parton et al., 1987). It was developed to simulate plant-soil carbon and nutrient dynamics and trace gas fluxes. It includes functions for nitrification and denitrification (Parton et al., 1996) and $\mathrm{CH}_{4}$ oxidation (Del Grosso et al., 2000). De Gryze et al. (2010) calibrated the DAYCENT model for the main field crops grown under California conditions using data from several long-term field experiments. 
The DAYCENT model represents biophysical processes at a geographical "point" characterized by its soil and climate conditions. We obtain regional averages by aggregating results over $12 \times 12 \mathrm{~km}$ grid cells that are assumed to be homogenous in terms of environmental characteristics. The DAYCENT model is run for the conditions prevailing in each cell over the years 1983-2008 for ten commonly observed crop rotations in the SV and the SJV. The average yield and GHG emission data for a given crop correspond to an average across rotations weighted by the observed rotation frequency. The use of the 1983-2001 period ensures that soil processes reach steady-state conditions under reference production practices, while alternative production practices are introduced in 2002 and maintained throughout 2008. Although studies consider carbon sequestration contracts of 20 years (Antle et al., 2003; Antle and Ogle, 2012), West and Six (2007)'s meta-analysis concludes that in most systems in California soil carbon sequestration reaches its steady state five to ten years after adopting new agricultural practices. Therefore, we do not expect the results to qualitatively change when extending the study duration beyond the current seven-year period. Values simulated in DAYCENT are aggregated to the scale of the economic model (each of the 27 SWAP regions) and averaged over the 2002-2008 period.

\section{B.2 Simulation}

For each crop, the DAYCENT model is run for $\mathrm{N}$ fertilizer and water application rates varying from 0 to $125 \%$ of the baseline rates in $25 \%$ increments and for the six tillage practices described in Appendix A. For each scenario, we record simulated yields and emissions of $\mathrm{CO}_{2}, \mathrm{~N}_{2} \mathrm{O}$, and $\mathrm{CH}_{4}$ associated with agricultural soil management. For each region-crop-GHG combination, we then estimate emission response functions $e_{\text {gil }}$ by fitting the following quadratic statistical model:

$e=\gamma_{0}+\gamma_{2} a_{2}+\gamma_{22}\left(a_{2}\right)^{2}+\gamma_{3} a_{3}+\gamma_{33}\left(a_{3}\right)^{2}+\gamma_{T} T+\gamma_{T T} T^{2}+\gamma_{23} a_{2} \times a_{3}+\gamma_{3 T} a_{3} \times T$,

where $a_{2}$ and $a_{3}$ are the irrigation and fertilizer rates, respectively, and $T$ is tillage intensity. Each regression is run with 27 observations. 55\% of coefficients (excluding $\gamma_{0}$ ) are statistically significant at the $10 \%$ level. Mean R-squared values across crop-region combinations are 0.96, 0.94, and 0.99 for $\mathrm{CO}_{2}, \mathrm{~N}_{2} \mathrm{O}$, 
and $\mathrm{CH}_{4}$, respectively.

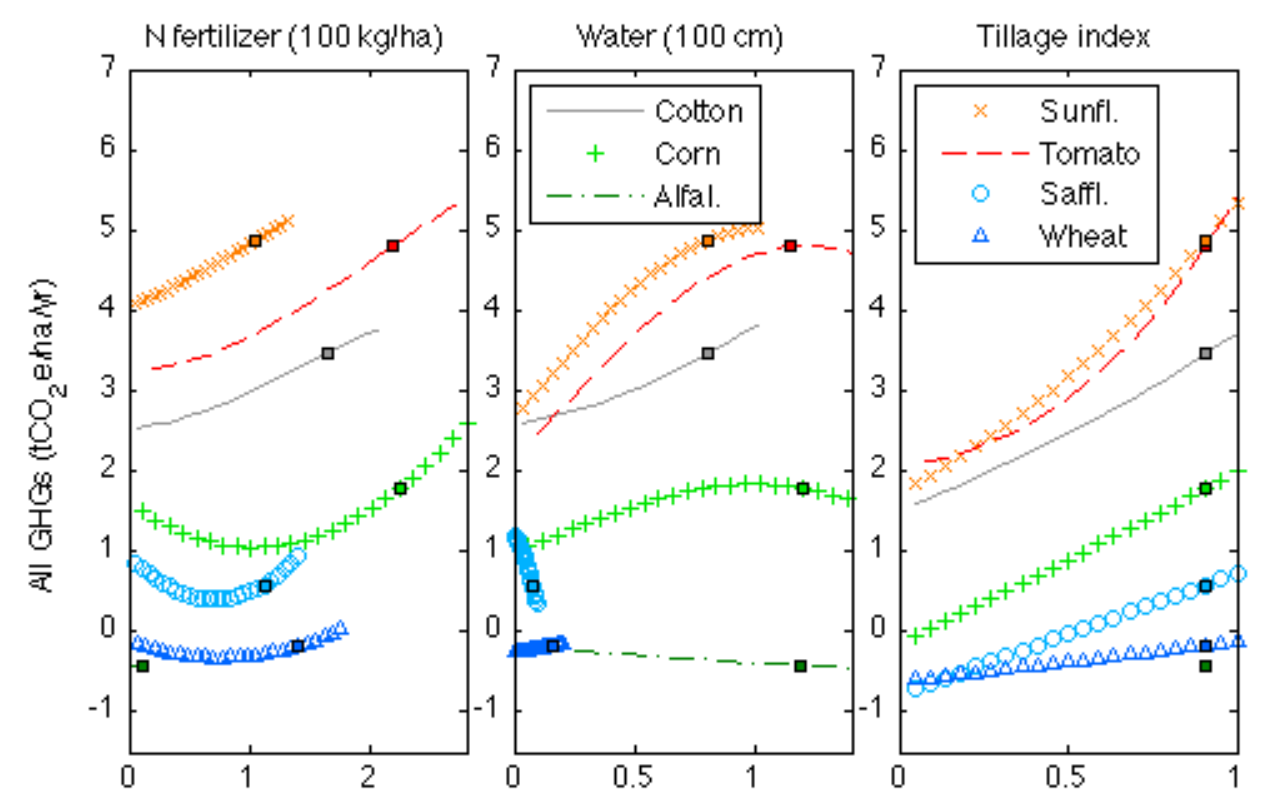

Figure B.1 Fitted partial emission factors for all GHGs combined and for the seven crops in region 5

Note: Squares indicate baseline practices. The range of irrigation and fertilizer rates considered goes from 0 to $125 \%$ of baseline rates. We ignore the $\mathrm{N}$ fertilizer and tillage responses for alfalfa, a N-fixing perennial crop.

Figure B.1 represents partial emission factors by crop for all GHGs combined as functions of a given practice, holding other practices at their reference value, for a representative region in the SV. In general, total GHG emissions increase with $\mathrm{N}$ fertilizer and water intensity. However, responses are non-monotonic for some crops, e.g., corn. In most regions, processing tomatoes, cotton and sunflower have large total emission rates relative to wheat, safflower, and alfalfa, while the emission rate of corn is moderate.

Figure B.2 depicts partial responses to production practices by crop for $\mathrm{CO}_{2}$ and $\mathrm{N}_{2} \mathrm{O}$ taken individually. ${ }^{37}$ Generally, changes in any of the three production practices considered significantly affect both $\mathrm{CO}_{2}$ and $\mathrm{N}_{2} \mathrm{O}$ emissions. Figure B.2 further shows that $\mathrm{N}$ fertilizer has a dual effect on GHG emissions: more $\mathrm{N}$

\footnotetext{
${ }^{37}$ Field emissions of $\mathrm{CH}_{4}$ are minimal and the partial emission functions for $\mathrm{CH}_{4}$ are not shown.
} 

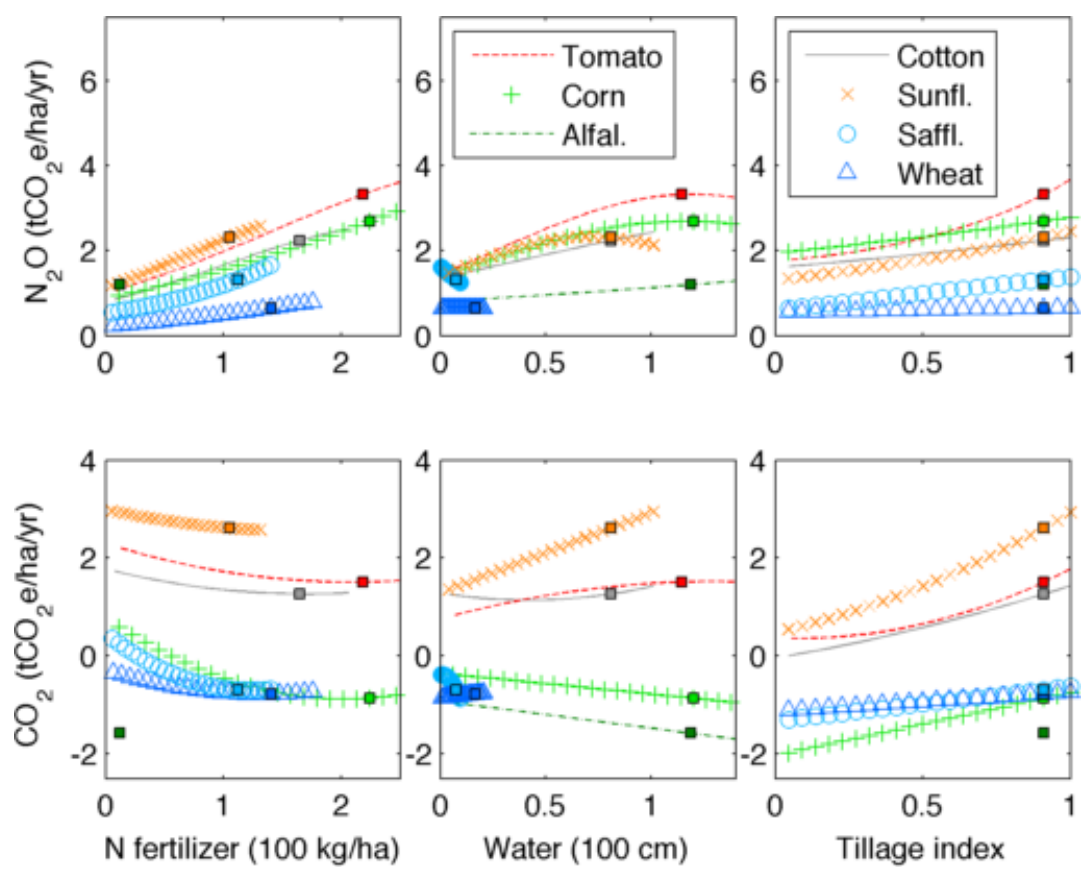

Figure B.2 Fitted partial $\mathrm{CO}_{2}$ and $\mathrm{N}_{2} \mathrm{O}$ emission factors for the seven crops in region 5

Note: Squares indicate baseline practices. The range of irrigation and fertilizer rates considered goes from 0 to $125 \%$ of baseline rates. We ignore the $\mathrm{N}$ fertilizer and tillage responses for alfalfa, a N-fixing perennial crop.

fertilizer increases $\mathrm{N}_{2} \mathrm{O}$ emissions but reduces $\mathrm{CO}_{2}$ emissions through enhanced crop growth and soil carbon sequestration. Water intensity affects both the $\mathrm{N}$ and $\mathrm{C}$ cycles and, thereby, both $\mathrm{CO}_{2}$ and $\mathrm{N}_{2} \mathrm{O}$ emissions. In particular, water intensity determines soil moisture, which in turn determines the oxygen level and how much nitrification and/or denitrification occurs - both leading to $\mathrm{N}_{2} \mathrm{O}$ production. Greater soil moisture also determines microbial activity and therefore available carbon, which affects denitrification. Furthermore, irrigation affects plant growth, which can lead to more carbon sequestration and also to more $\mathrm{N}$ uptake and therefore lower $\mathrm{N}_{2} \mathrm{O}$ emissions. As a result of these combined effects, emissions of $\mathrm{N}_{2} \mathrm{O}$ and $\mathrm{CO}_{2}$ may respond differently to increased irrigation intensity across different crops. These findings illustrate the importance of relying on biophysical process-based models and accounting for all GHGs when modeling the abatement potential of cropping systems. 
Spatially aggregated emission factors: The conditional GHG emission rates and input and tillage intensities are aggregated at the valley or state level $v(g)$ using crop acreages as weights. The valley and state emission response functions $\tilde{e}_{v(g) i l}$ are obtained by fitting a model that is quadratic in production practices and includes interaction terms as for the previously derived region-level emission functions.

\section{Calibration of the production model}

We drop the regional index $g$ for notational clarity. We begin with the derivation of the cost functions $c_{i T}$. Calibration of the model represented by program (2) is then completed sequentially, as the choice of reference shadow values $\bar{\lambda}$ depends on the choice of returns-to-scale parameters $\boldsymbol{\delta}$, which itself depends on the choice of substitution elasticities $\overline{\boldsymbol{\sigma}}$.

\section{C.1 Cost responses to tillage intensity $\left(c_{i T}\right)$}

The regional tillage cost $c_{i T}$ represents the per hectare costs of labor, machinery, fuel, and extra herbicide utilized for tillage activities. Reduced tillage systems are characterized by fewer pre-planting and/or post-harvest operations; however, no-till systems require one additional herbicide spraying operation to compensate for the lack of mechanical weed removal (van Kessel et al., 2013; Robertson et al., 2014).

The cost of California conventional tillage practices (CA-CT) is observed in the Agricultural cost and return studies (UCCE, 2007). We use Mitchell et al. (2009) and experts' opinions to assess the costs of the five alternative tillage practices described in Table A.1. Specifically, we modify the type of equipment used, the number of tractor passes, and the cost increase for no-till systems due to one additional passage of herbicide spraying. These modified practices translate into new equipment, labor, fuel costs, and chemicals associated with each alternative tillage system.

We then estimate, for each region and crop, the tillage cost response to changes in the tillage index by fitting a quadratic model on these six data points. The 
fitted tillage cost function $c_{i T}$ is strictly convex for all region-crop combinations. We do not model tillage choice for alfalfa since it is cultivated as a perennial.

\section{C.2 Yield elasticities $\left(\overline{\mathbf{y}}_{2}\right.$ and $\left.\overline{\mathbf{y}}_{3}\right)$}

We estimate the partial yield responses to $\mathrm{N}$ fertilizer and water by fitting nonlinear functions to the conditional yield data generated with the DAYCENT model at the level of each SWAP region. Following Godard et al. (2008) and Mérel et al. (2014), we fit an exponential function to the $\mathrm{N}$ fertilizer-yield relationship, holding the irrigation rate and the tillage intensity at their baseline values:

$$
y\left(a_{3}\right)=\gamma_{03}+\gamma_{13}\left(1-e^{-\gamma_{23} a_{3}}\right)
$$

where $y$ is yield, $a_{3}$ is the $\mathrm{N}$ fertilizer application rate and $\gamma_{03}, \gamma_{13}$ and $\gamma_{23}$ are the regression parameters.

Following Mérel et al. (2014), we estimate a sigmoid yield response curve to the water application rate, holding the $\mathrm{N}$ fertilizer rate and the tillage intensity at their baseline values:

$$
y\left(a_{2}\right)=\frac{\gamma_{12}}{1+e^{-\frac{a_{2}-\gamma_{02}}{\gamma_{22}}}}
$$

where $a_{2}$ is the water application rate and $\gamma_{02}, \gamma_{12}$ and $\gamma_{22}$ are the regression parameters.

Using expressions (C-1) and (C-2), we evaluate the agronomic yield elasticities with respect to water and $\mathrm{N}$ fertilizer at the reference application rates. The yield of alfalfa does not significantly respond to $\mathrm{N}$ fertilizer, therefore we do not model changes in the $\mathrm{N}$ input for this crop. Table C.1 reports average yield elasticities at the level of the SV and the SJV.

\section{C.3 Substitution elasticities $(\bar{\sigma})$ and substitution param- eters $(\rho)$}

Because our economic production model assumes the same substitution elasticity between any two explicit inputs, while our partial yield response functions do not, we employ three alternative methods to calibrate the substitution elasticities 
Table C.1 Mean yield elasticities in the SV and the SJV

\begin{tabular}{lcccc}
\hline \multirow{2}{*}{ Crop } & \multicolumn{2}{c}{ Sacramento Valley } & \multicolumn{2}{c}{ San Joaquin Valley } \\
\cline { 2 - 5 } & $\bar{y}_{i 2}$ & $\bar{y}_{i 3}$ & $\bar{y}_{i 2}$ & $\bar{y}_{i 3}$ \\
\hline \multirow{2}{*}{ Alfalfa } & 0.20 & - & 0.25 & - \\
\multirow{3}{*}{ Corn } & $(0.03)$ & - & $(0.05)$ & - \\
& 0.23 & 0.13 & 0.28 & 0.13 \\
Cotton & $(0.03)$ & $(0.03)$ & $(0.05)$ & $(0.03)$ \\
\multirow{3}{*}{ Wheat } & 0.46 & 0.03 & 0.57 & 0.01 \\
\multirow{4}{*}{ Sunflower } & $(0.03)$ & $(0.01)$ & $(0.07)$ & $(0.01)$ \\
\multirow{3}{*}{ Processing tomatoes } & 0.12 & 0.03 & 0.31 & $5 \mathrm{e}-03$ \\
\multirow{3}{*}{ Safflower } & $(0.03)$ & $(0.01)$ & $(0.15)$ & $(3 \mathrm{e}-03)$ \\
& 0.46 & $5 \mathrm{e}-05$ & 0.78 & $6 \mathrm{e}-05$ \\
& $(0.04)$ & $(5 \mathrm{e}-05)$ & $(0.09)$ & $(1 \mathrm{e}-04)$ \\
& $0.04)$ & 0.02 & 0.35 & 0.04 \\
& 0.22 & 0.14 & $0.03)$ & $(0.03)$ \\
& $(0.04)$ & $(0.05)$ & $(0.08)$ & 0.26 \\
& & & & \\
\hline
\end{tabular}

Note: $\bar{y}_{i 2}$ denotes the yield elasticity with respect to water; $\bar{y}_{i 3}$ denotes the yield elasticity with respect to fertilizer. Standard deviations are indicated in brackets.

$\overline{\boldsymbol{\sigma}}$, using either the minimum of the land-water and land-fertilizer agronomic elasticities, or the maximum, or the average. Our main marginal abatement cost curves are shown for the model calibrated using the average of the two values. In Appendix D.1 we report results obtained using the two other calibration rules.

We exploit the rich set of crop- and region-specific partial yield response functions derived in Appendix C.2 to calibrate the substitution elasticity parameters of our economic model. The calibration procedure makes use of the fact that the concavity properties of the partial yield response functions to irrigation and $\mathrm{N}$ fertilizer can be related to the substitution elasticities between land and water and between land and fertilizer, respectively. Specifically, one can easily show that given the CES production function used in model (2), the second-order yield elasticity with respect to water (that is, the elasticity of the water-yield elasticity with respect to water intensity) is equal to $\bar{y}_{i 22}=\left(\frac{\sigma_{i}-1}{\sigma_{i}}\right)\left(1-\frac{\bar{y}_{i 2}}{\delta_{i}}\right)$, where $\bar{y}_{i 2}$ denotes the yield elasticity with respect to water. A similar expression can 
be obtained for the second-order yield elasticity with respect to $\mathrm{N}$ fertilizer. ${ }^{38}$ Therefore, conditional on the returns-to-scale parameter $\delta_{i}$ one can derive a value of $\sigma_{i}$ from knowledge of the first- and second-order partial yield elasticities of the fitted agronomic yield response curves.

Table C.2 Mean substitution elasticities in the SV and the SJV for the three calibration rules

\begin{tabular}{lcccccc}
\hline \multirow{2}{*}{ Crop } & \multicolumn{3}{c}{ Sacramento Valley } & \multicolumn{3}{c}{ San Joaquin Valley } \\
\cline { 2 - 7 } & average & min & $\max$ & average & $\min$ & $\max$ \\
\hline \multirow{2}{*}{ Alfalfa } & 0.14 & 0.14 & 0.14 & 0.06 & 0.06 & 0.06 \\
\multirow{4}{*}{ Corn } & $(0.02)$ & $(0.02)$ & $(0.02)$ & $(0.03)$ & $(0.03)$ & $(0.03)$ \\
& 0.21 & 0.12 & 0.30 & 0.19 & 0.08 & 0.29 \\
Cotton & $(0.01)$ & $(9 \mathrm{e}-03)$ & $(0.02)$ & $(0.02)$ & $(0.02)$ & $(0.03)$ \\
& 0.15 & 0.04 & 0.25 & 0.10 & 0.02 & 0.19 \\
Wheat & $(0.02)$ & $(0.01)$ & $(0.03)$ & $(0.02)$ & $(2 \mathrm{e}-03)$ & $(0.03)$ \\
\multirow{4}{*}{ Sunflower } & 1.00 & 0.24 & 1.75 & 0.13 & 0.08 & 0.18 \\
\multirow{3}{*}{ Processing tomatoes } & $(0.18)$ & $(0.01)$ & $(0.35)$ & $(0.06)$ & $(0.08)$ & $(0.05)$ \\
\multirow{4}{*}{ Safflower } & 0.05 & 0.02 & 0.10 & 0.03 & 0.02 & 0.06 \\
& $(5 \mathrm{e}-03)$ & $(0.00)$ & $(0.01)$ & $(0.02)$ & $(0.00)$ & $(0.04)$ \\
& 0.13 & 0.03 & 0.23 & 0.13 & 0.03 & 0.24 \\
& 1.17 & $(7 \mathrm{e}-03)$ & $(0.01)$ & $(0.02)$ & $(0.01)$ & $(0.03)$ \\
& $(0.02)$ & 0.35 & 2.00 & 0.33 & 0.15 & 0.51 \\
& & $(0.04)$ & $(0.00)$ & $(0.05)$ & $(0.04)$ & $(0.06)$ \\
\hline
\end{tabular}

Note: Standard deviations are indicated in brackets.

Because our economic production functions imply identical substitution elasticities across inputs, whereas the two agronomically-derived substitution elasticities need not be identical, we set the substitution elasticity equal to either the minimum of the two agronomic values (the most conservative approach), or the maximum (truncated at a value of 2 for a very small number of crop-region combinations with very large implied values), or the average. The average values for each crop obtained from our agronomic data are reported in Table C.2 for each of the three calibration rules. For alfalfa, all three values are identical because there is no yield response to $\mathrm{N}$ fertilizer.

The substitution elasticity values appear very reasonable compared to those

\footnotetext{
${ }^{38}$ Derivation available upon request to the authors.
} 
found in the related literature. Studies in California have used substitution elasticities ranging from 0.17 to 0.70 (Howitt, 1995a; Howitt et al., 2012). Mérel et al. (2014) choose a mean substitution elasticity of 0.20 for a study area located in the SV. Calzadilla et al. (2011) calibrate regional agricultural production functions using substitution elasticities between land and water ranging between 0.04 and 0.14 depending on the world region. Hertel et al. (1996) estimate the landnitrogen substitution elasticity for corn to be around 1.15 in Indiana.

Once the choice of substitution elasticity $\bar{\sigma}_{i}$ has been made, the CES parameter $\rho_{i}$ is simply set equal to $\frac{\bar{\sigma}_{i}-1}{\bar{\sigma}_{i}}$.

\section{C.4 Supply elasticities $(\bar{\eta})$ and returns-to-scale parame- ters $(\delta)$}

Exact calibration to a set of supply elasticities $\overline{\boldsymbol{\eta}}$ is achieved by choice of the returns-to-scale parameters $\boldsymbol{\delta} \in(0,1)^{I}$. Because the shadow values of binding constraints are affected by changes in output price, in each region elasticity calibration requires solving a non-linear system of $I$ equations relating the entire set of parameters $\boldsymbol{\delta}$ to the vector of exogenous elasticities $\overline{\boldsymbol{\eta}}$. Mérel et al. (2011) and Garnache and Mérel (2015) have shown that this system has a unique solution only for certain values of $\overline{\boldsymbol{\eta}}$. The set of reproducible elasticities depends on the reference input-output allocation $(\overline{\mathbf{q}}, \overline{\mathbf{x}})$ and on model structure. Although our model includes tillage adjustments, a refinement over these earlier studies, calibration of supply elasticities is subject to the same calibration conditions because tillage does not affect crop yields in our model.

Since we wish to specify models with varying degrees of input substitution, and since elasticity calibration is eased by input substitutability (Mérel et al., 2011), we adopt the most stringent set of calibration conditions corresponding to a model with no substitution $(\overline{\boldsymbol{\sigma}}=0)$. This choice allows us to calibrate models with different sets of substitution elasticities to the same set of supply elasticities, no matter how small the values of the $\bar{\sigma}_{i}$ parameters are. As in Mérel et al. (2011), we require myopic calibration to be feasible to ensure uniqueness of the set of calibrating parameters. The calibration conditions and attendant calibration system are derived in Garnache and Mérel (2015) and we refer the 
Table C.3 Mean own-price supply elasticity priors and regional reproducible elasticities.

\begin{tabular}{|c|c|c|c|}
\hline \multirow[b]{2}{*}{ Crop } & \multirow[b]{2}{*}{ Statewide prior } & \multicolumn{2}{|c|}{ Modeled regional elasticities } \\
\hline & & Sacramento Valley & San Joaquin Valley \\
\hline \multirow{2}{*}{ Alfalfa } & \multirow{2}{*}{0.51} & 0.51 & 0.51 \\
\hline & & $(0.00)$ & $(0.01)$ \\
\hline \multirow{2}{*}{ Corn } & \multirow{2}{*}{0.45} & 0.59 & 0.71 \\
\hline & & $(0.10)$ & $(0.17)$ \\
\hline \multirow{2}{*}{ Cotton } & \multirow{2}{*}{0.64} & 0.96 & 1.48 \\
\hline & & $(0.14)$ & $(0.47)$ \\
\hline \multirow{2}{*}{ Wheat } & \multirow{2}{*}{0.38} & 0.38 & 0.62 \\
\hline & & $(0.00)$ & $(0.33)$ \\
\hline \multirow{2}{*}{ Sunflower } & \multirow{2}{*}{0.34} & 0.86 & 4.39 \\
\hline & & $(0.15)$ & $(2.40)$ \\
\hline \multirow{2}{*}{ Processing tomatoes } & \multirow{2}{*}{0.28} & 0.36 & 0.68 \\
\hline & & $(0.09)$ & $(0.26)$ \\
\hline \multirow{2}{*}{ Safflower } & \multirow{2}{*}{0.34} & 0.58 & 1.44 \\
\hline & & $(0.06)$ & $(0.48)$ \\
\hline
\end{tabular}

Note: Standard deviations are indicated in brackets.

reader to their paper for more information.

In our empirical application, these calibration conditions are violated in several instances, which forces us to adjust the regional target elasticities away from the initial prior so as to allow for model calibration. Table C.3 shows the supply elasticity priors and the resulting average reproducible elasticities in the SV and the SJV.

\section{C.5 Remaining CES parameters ( $\alpha$ and $\beta$ )}

The parameters $\boldsymbol{\alpha}$ and $\boldsymbol{\beta}$ are easily recovered on a crop-by-crop basis by equating the yield elasticities implied by the CES production function to the reference values $\overline{\mathbf{y}}_{2}$ and $\overline{\mathbf{y}}_{3}$ and using the relationships $\sum_{j} \beta_{i j}=1$ and $\bar{q}_{i}=\alpha_{i}\left(\sum_{j} \beta_{i j} \bar{x}_{i j}^{\rho_{i}}\right)^{\frac{\delta_{i}}{\rho_{i}}}$. These parameters thus depend on $\bar{\sigma}_{i}$ and $\delta_{i}$.

Figures C.1 and C.2 depict the resulting calibrated CES yield response curves together with the fitted agronomic response curves for a selected region in the 

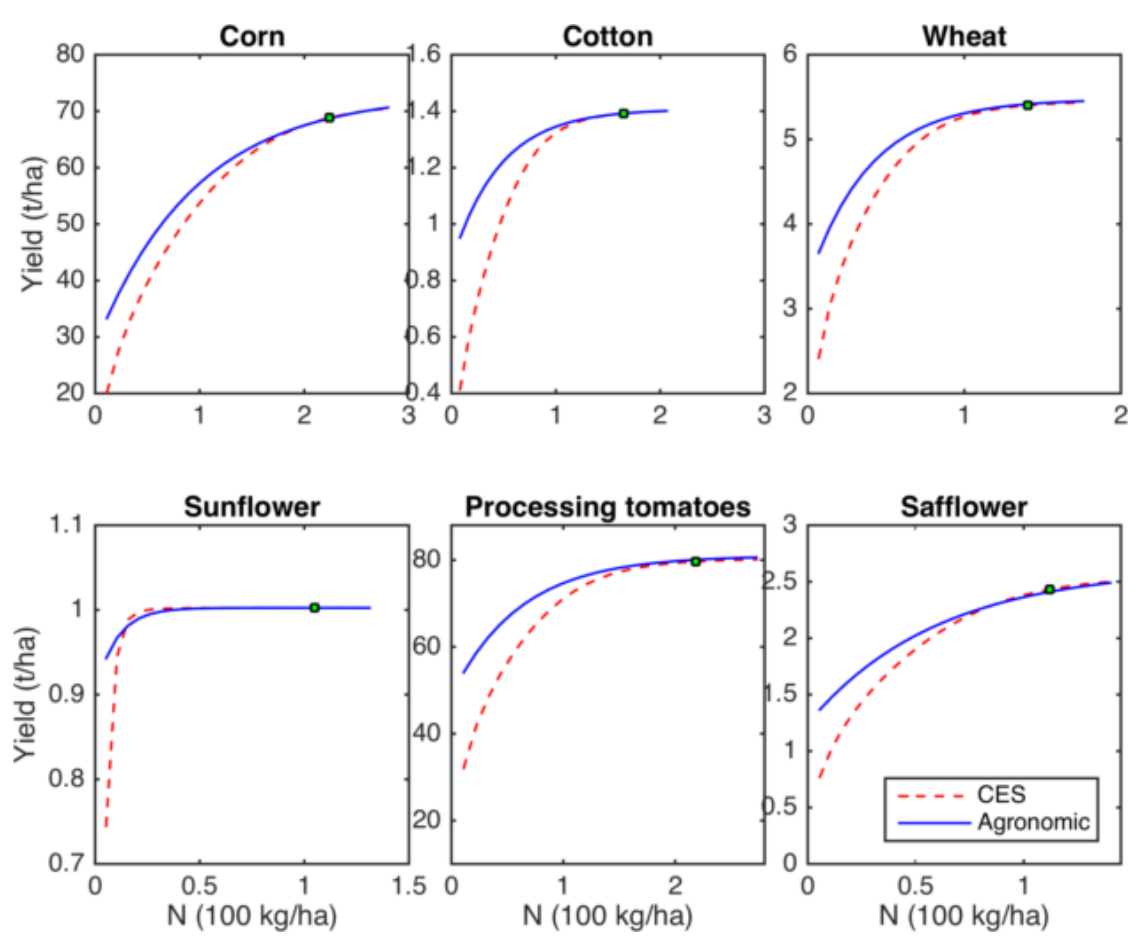

Figure C.1 Yield responses to $\mathrm{N}$ fertilizer application in region 5

Note: Squares indicate the baseline. The yield of alfalfa is not responsive to $\mathrm{N}$ fertilizer.

SV.

\section{C.6 Shadow prices $(\bar{\lambda})$ and shadow costs $(\mu)$}

Using the definition of the yield elasticities with respect to water and $\mathrm{N}$ fertilizer, the first-order conditions to program (2) (without the emission cap) can be conveniently written as:

$$
\left\{\begin{array}{l}
p_{i} \bar{q}_{i}\left(\delta_{i}-\bar{y}_{i 2}-\bar{y}_{i 3}\right)=\left(c_{i T}\left(\bar{T}_{i}\right)+\mu_{i T} \bar{T}_{i}+c_{i 1}+\mu_{i 1}+\bar{\lambda}_{1}\right) \bar{x}_{i 1} \\
p_{i} \bar{q}_{i} \bar{y}_{i 2}=\left(c_{i 2}+\mu_{i 2}+\bar{\lambda}_{2}\right) \bar{x}_{i 2} \\
p_{i} \bar{q}_{i} \bar{y}_{i 3}=\left(c_{i 3}+\mu_{i 3}\right) \bar{x}_{i 3} \\
0=c_{i T}^{\prime}\left(\bar{T}_{i}\right)+\mu_{i T}
\end{array} .\right.
$$

The system of conditions (C-3) shows that the shadow costs $\mu_{i 3}$ and $\mu_{i T}$ are identified from the reference conditions and the calibration information whereas the shadow costs $\mu_{i 1}$ and $\mu_{i 2}$ are only identified up to a scalar due to the shadow values 

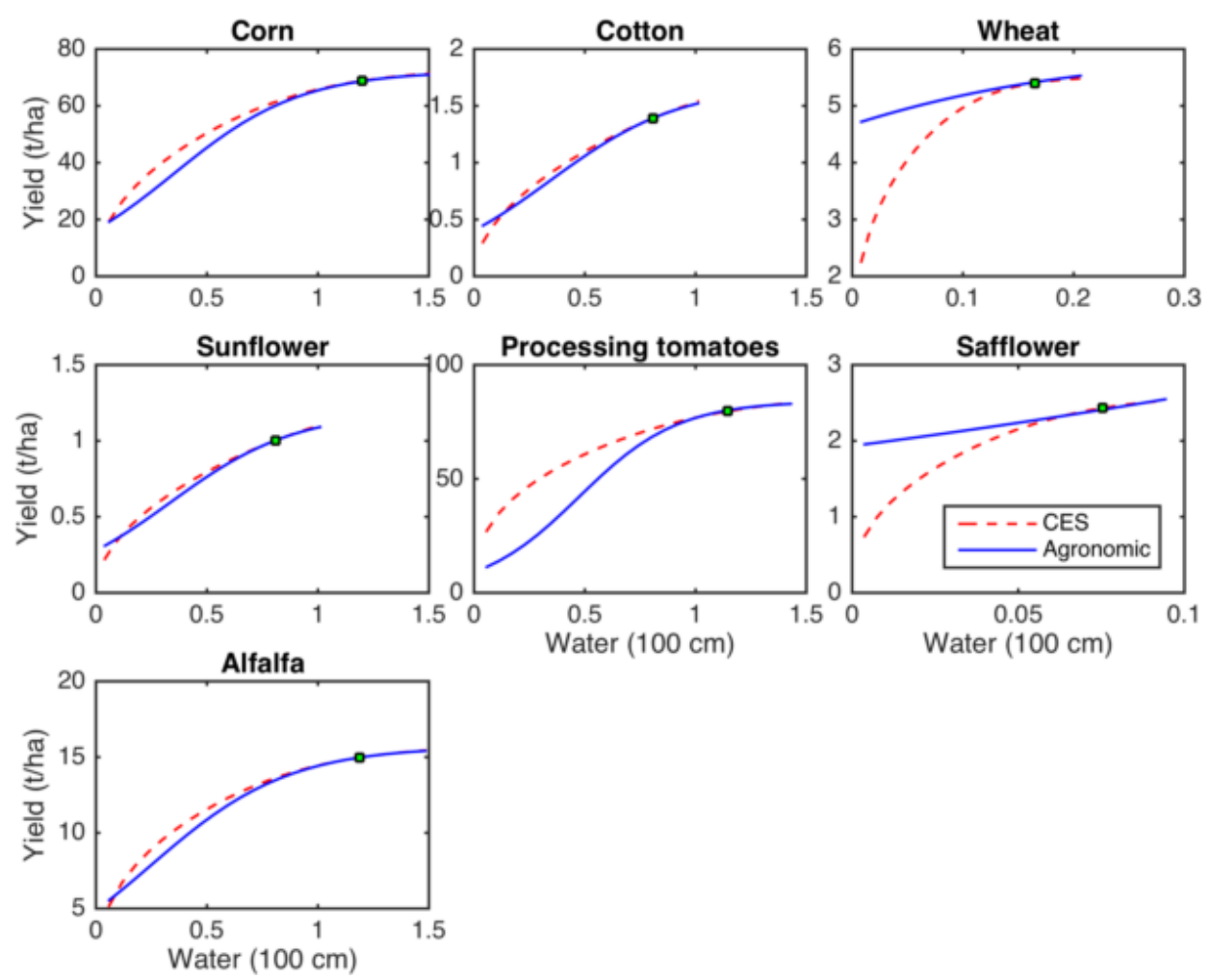

Figure C.2 Yield responses to water application in region 5 Note: Squares indicate the baseline.

on land and water, respectively. Our strategy to resolve this under-determinacy is to choose $\overline{\boldsymbol{\lambda}}$ so as to minimize the sum of shadow expenditures on land and water required to satisfy conditions (C-3). That is, in each region we solve, for $j=1,2$ :

$$
\min _{\bar{\lambda}_{j} \geq 0} \sum_{i}\left(\mu_{i j} \bar{x}_{i j}\right)^{2}
$$

where $\mu_{i j} \bar{x}_{i j}$ is obtained from (C-3). Weighted averages of the resulting shadow costs $\boldsymbol{\mu}$ across the SV and the SJV are shown in Table C.4. 
Table C.4 Average cost data and shadow costs in the SV and the SJV

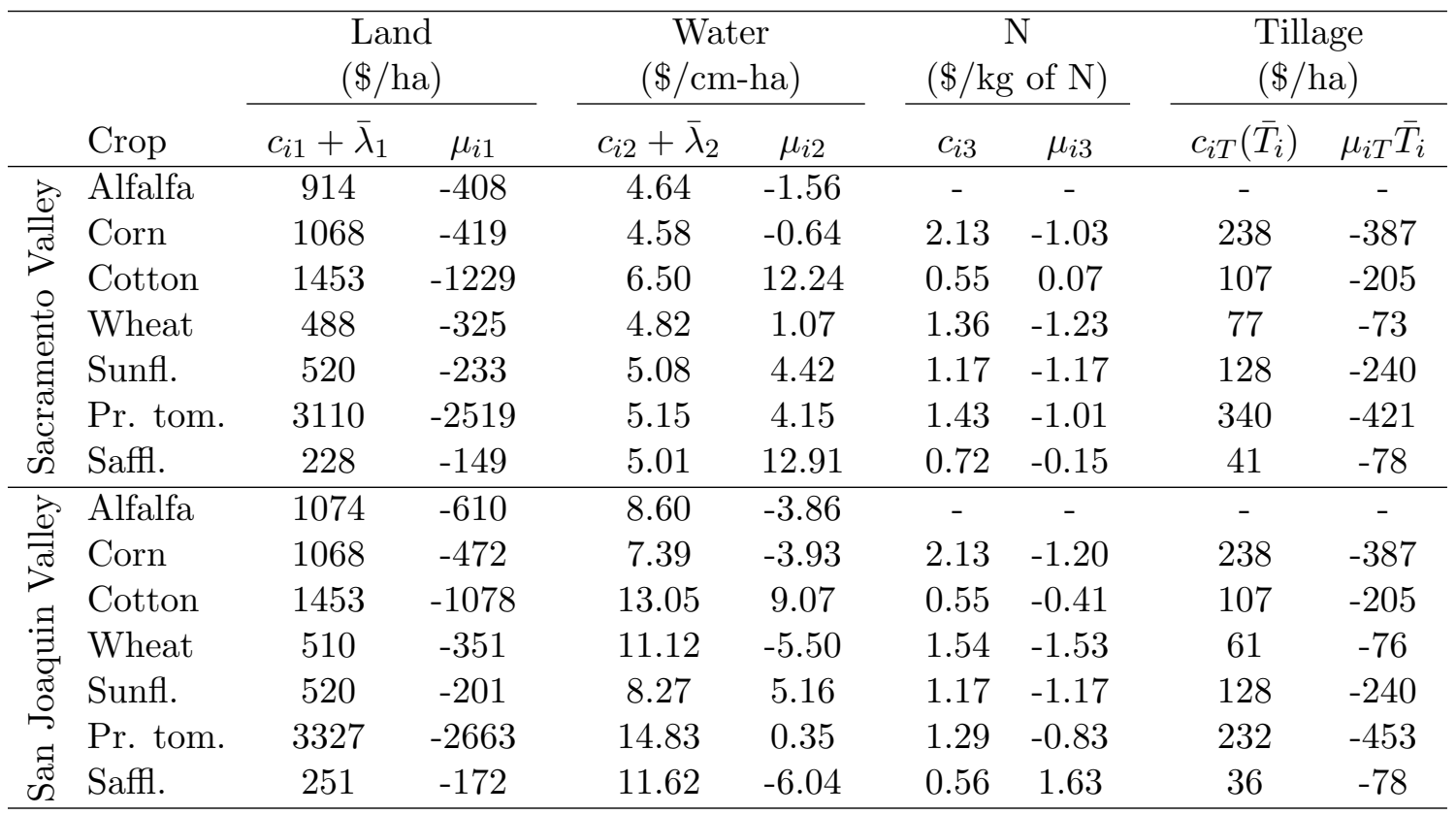

Note: We ignore the $\mathrm{N}$ fertilizer and tillage responses for alfalfa, a $\mathrm{N}$-fixing perennial crop.

\section{Robustness checks}

\section{D.1 Substitution elasticities}

Our baseline model calibration sets the substitution elasticities equal to the average of the land-water and land-fertilizer substitution elasticities implied by the agronomic yield response functions derived from DAYCENT data. To investigate the sensitivity of our findings to the choice of substitution elasticities, we re-run the first-best and second-best programs by setting the substitution elasticities $\bar{\sigma}_{g i}$ equal to either the minimum or the maximum of the two agronomically-derived values (truncated at a value of 2 for a very small number of crop-region combinations with very large implied values).

Marginal GHG abatement cost schedules under the first-best policy are depicted in Figure D.1.

Abatement levels at a social price of $\$ 20 / \mathrm{tCO}_{2} \mathrm{e}$ increase with the value of $\bar{\sigma}_{g i}$ for all policies as a result of more important adjustments along the intensive 


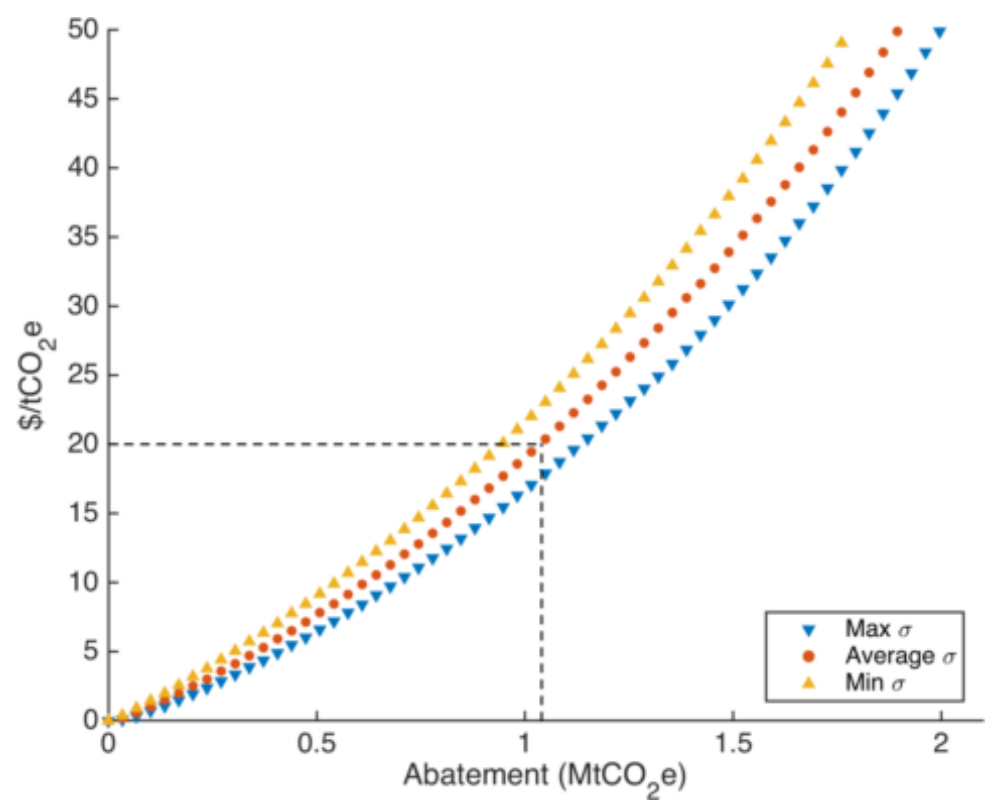

Figure D.1 Marginal abatement costs under the first-best policy for three sets of substitution elasticities

margin, as reported in Table D.1. However, this effect is less noticeable for policies that do not provide strong incentives to change water or $\mathrm{N}$ intensities such as policies regulating tillage or carbon sequestration. In contrast, the relative performance of policies directly targeting $\mathrm{N}$ fertilizer is quite sensitive to the assumed value of the substitution elasticity. Despite these differences, the key policy comparisons are robust to the value of $\bar{\sigma}_{g i}$. In particular, policies targeting a single input remain unattractive even for the highest value of $\bar{\sigma}_{g i}$ considered.

The social costs associated with a $1 \mathrm{MtCO}_{2} \mathrm{e}$ abatement target are reported in Table D.2 for the first-best and second-best policies. Irrespective of the choice of $\bar{\sigma}_{g i}$, second-best policies using spatially aggregated emission factors perform better than policies regulating a single GHG, which themselves outperform policies regulating a single input. Regulating $\mathrm{N}$ and tillage simultaneously partly mitigates the distortions arising from the single tax schemes. 
Table D.1 GHG emissions abated in $\mathrm{MtCO}_{2} \mathrm{e}$ at $\$ 20 / \mathrm{tCO}_{2} \mathrm{e}$ under the first-best and second-best policies for two alternative levels of the substitution elasticity - the minimum or maximum of the two agronomically-derived substitution elasticities

\begin{tabular}{ccccccccc}
\hline & & \multicolumn{5}{c}{ Second-best policies } \\
\cline { 3 - 8 } $\bar{\sigma}_{g i}$ & $\begin{array}{c}\text { First-best } \\
\text { policy }\end{array}$ & \multicolumn{2}{c}{$\begin{array}{c}\text { Spatially aggr. } \\
\text { emission factors }\end{array}$} & \multicolumn{2}{c}{$\begin{array}{c}\text { Regulation of } \\
\text { a single }\end{array}$} & \multicolumn{3}{c}{$\begin{array}{c}\text { Regulation } \\
\text { of inputs }\end{array}$} \\
\cline { 3 - 9 } & & Valley & $\mathrm{CA}$ & $\mathrm{CO}_{2}$ & $\mathrm{~N}_{2} \mathrm{O}$ & Tillage & $\mathrm{N}$ & Till. \& N \\
\hline $\min$ & 0.95 & 0.88 & 0.86 & 0.80 & 0.81 & 0.46 & 0.07 & 0.51 \\
$\max$ & 1.13 & 1.06 & 1.02 & 0.83 & 0.96 & 0.48 & 0.23 & 0.66 \\
\hline
\end{tabular}

Note: Results for the average substitution elasticity (the preferred model) are reported in Table 3.

Table D.2 Social costs of the first-best and second-best policies associated with a 1 $\mathrm{MtCO}_{2} \mathrm{e}$ abatement target, for two alternative levels of the substitution elasticity - the minimum or maximum of the two agronomically-derived substitution elasticities

\begin{tabular}{|c|c|c|c|c|c|c|c|}
\hline \multirow{3}{*}{$\bar{\sigma}_{g i}$} & \multirow{3}{*}{$\begin{array}{c}\text { First-best } \\
\text { policy }\end{array}$} & \multicolumn{6}{|c|}{ Second-best policies } \\
\hline & & \multicolumn{2}{|c|}{$\begin{array}{l}\text { Spatially aggregated } \\
\text { emission factors }\end{array}$} & \multicolumn{2}{|c|}{$\begin{array}{l}\text { Regulation of } \\
\text { a single GHG }\end{array}$} & \multicolumn{2}{|c|}{$\begin{array}{l}\text { Regulation } \\
\text { of inputs }\end{array}$} \\
\hline & & Valley & $\mathrm{CA}$ & $\mathrm{CO}_{2}$ & $\mathrm{~N}_{2} \mathrm{O}$ & Tillage & Tillage \& N \\
\hline $\min$ & 0.49 & 0.52 & 0.53 & 0.62 & 0.60 & 1.06 & 0.97 \\
\hline $\max$ & 0.36 & 0.38 & 0.39 & 0.55 & 0.45 & 1.01 & 0.74 \\
\hline
\end{tabular}

Note: Values are expressed as a percentage of baseline agricultural profit. Results for the average substitution elasticity (the preferred model) are presented in Table 3.

\section{D.2 Supply elasticities}

Marginal GHG abatement cost schedules under the first-best policy are depicted in Figure D.2 for the own-price supply elasticity priors reported in Table C.3 and for alternative sets of supply elasticities corresponding to the priors times (resp. divided by) a factor of 4 and denoted "prior*4" (resp. "prior/4"). Second-best curves are available upon request.

\section{D.3 Reference shadow values}

Marginal GHG abatement cost schedules under the first-best policy are depicted in Figure D.3 for reference shadow values $\bar{\lambda}_{j}$ chosen so as to minimize the sum of squared shadow expenditures $\sum_{i}\left(\mu_{i j} \bar{x}_{i j}\right)^{2}$ (denoted "Min sum of squares") or as 


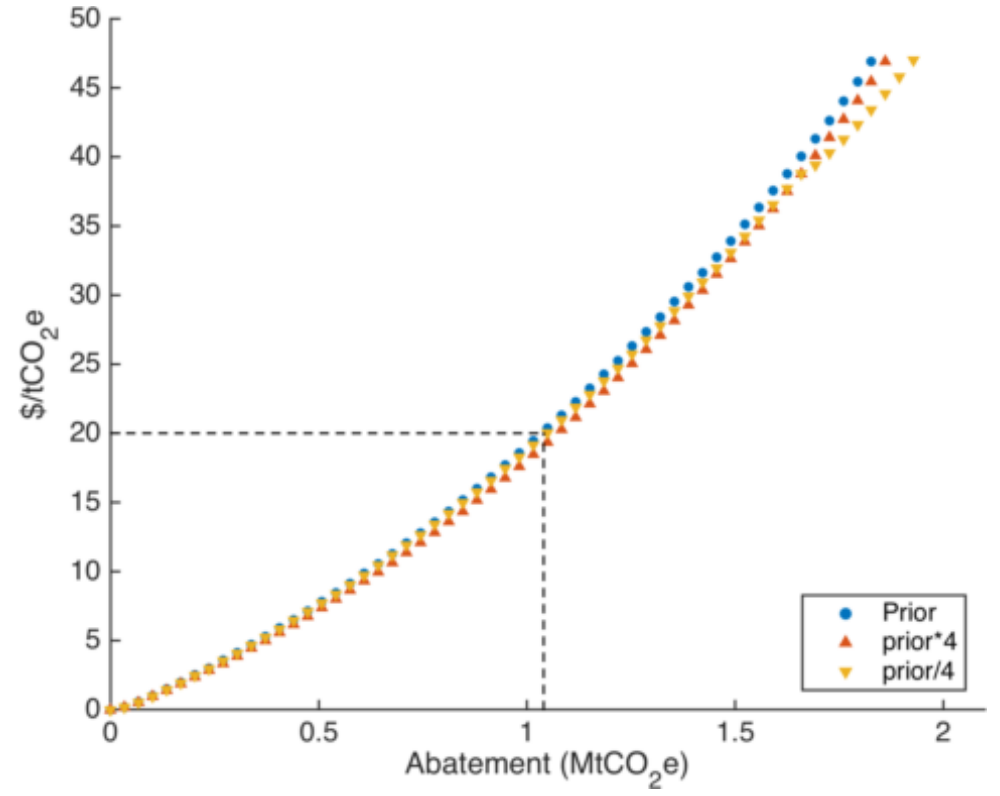

Figure D.2 Marginal abatement costs under the first-best policy for three sets of own-price supply elasticity priors

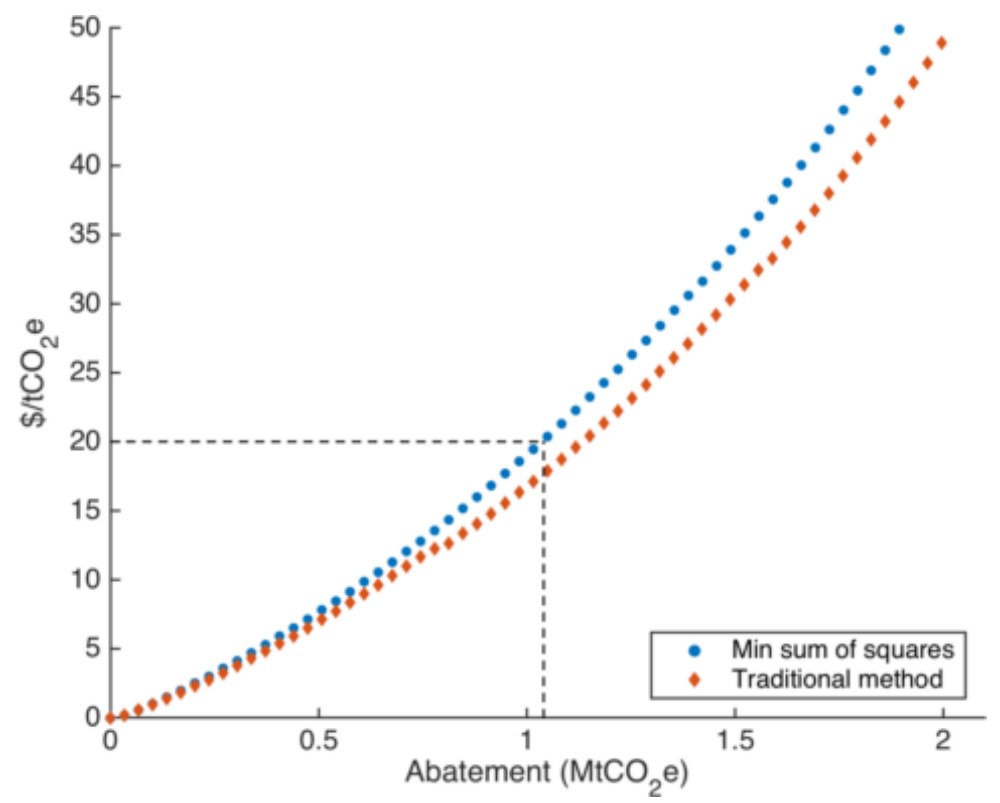

Figure D.3 Marginal abatement costs under the first-best policy for two sets of reference shadow values 
determined by the traditional method of Howitt (1995b) (denoted "Traditional method"). Second-best curves are available upon request.

\section{D.4 Endogenous crop prices}

We run an alternative model with endogenous crop prices where constant-elasticity residual demand functions are specified for each crop at the level of the Central Valley. For the purpose of calibration, statewide crop prices are computed by weighing regional prices with observed output levels. The parameters of each residual demand function are determined from observed output at the statewide price and a set of crop-specific demand elasticities used in SWAP that are reproduced in Table D.3. The difference between the regional price and the statewide price is then interpreted as a transaction cost per unit of regional output (that may be negative). The abatement allocation program maximizes the sum across crops of willingnesses to pay minus total production costs and transaction costs, subject to the constraints already present in program (2).

Table D.3 Crop-specific residual demand elasticities

\begin{tabular}{lc}
\hline Crop & Elasticity \\
\hline Alfalfa & -2 \\
Corn & -20 \\
Cotton & -20 \\
Wheat & -20 \\
Sunflower & -5 \\
Processing tomatoes & -6 \\
Safflower & -5 \\
\hline
\end{tabular}

Figure D.4 plots the resulting first-best marginal abatement cost curve against that obtained from the model with exogenous prices. Table D.4 reports the social costs of abating $1 \mathrm{MtCO}_{2} \mathrm{e}$ in the first- and second-best scenarios, for models with exogenous or endogenous crop prices. 


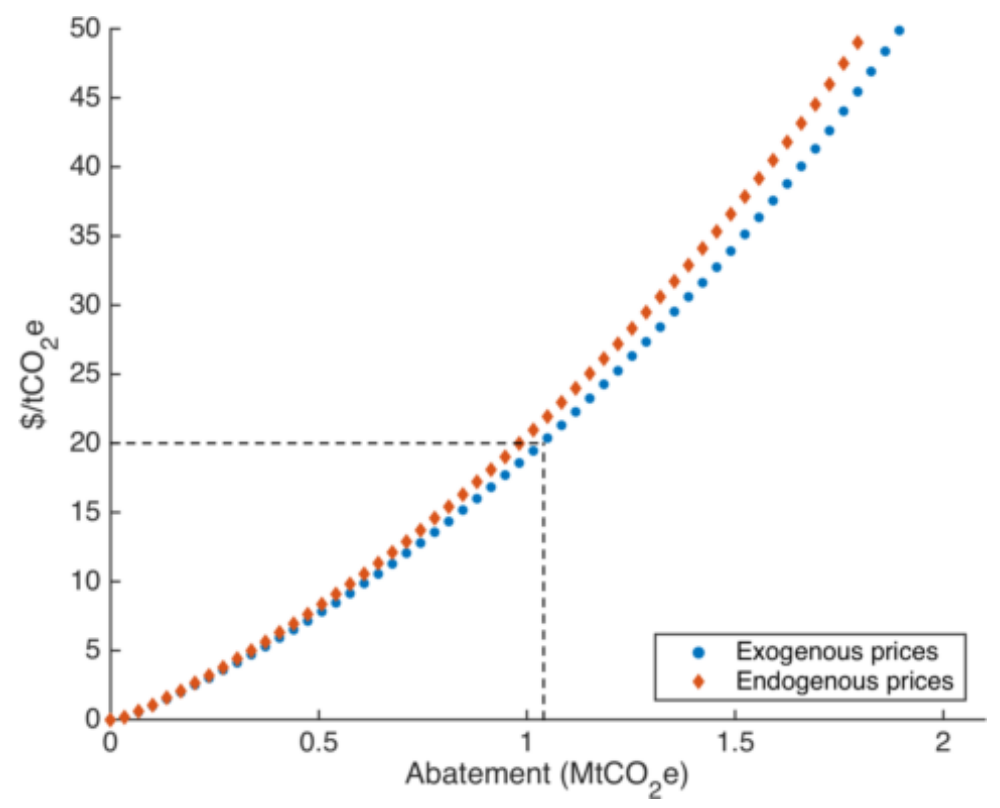

Figure D.4 Marginal abatement costs under the first-best policy assuming exogenous or endogenous crop prices

\section{E Additional results for the first-best policy}

\section{E.1 Spatial heterogeneity in the emission generation pro- cess}

Table E.1 provides information on spatial heterogeneity in the emission generation process by showing crop-specific emission rates in the baseline and at a marginal cost of $\$ 20 / \mathrm{tCO}_{2} \mathrm{e}$ for the SV and the SJV. The absolute emission rates vary between the two valleys. For example, alfalfa is a net emitter in the SV but a net sequester in the SJV, and corn and safflower show baseline emission rates over twice as high in the SV as in the SJV. These regional differences are largely driven by variation in climate and soils and, to a lesser extent, by differences in baseline production practices between the two valleys. Despite these differences in absolute emission rates, in both valleys the three highest emitters in the baseline are processing tomatoes, sunflower, and cotton, while the three lowest emitters are wheat, safflower and alfalfa. In addition, in both valleys the largest average 
Table D.4 Social costs of the first-best and second-best policies associated with a 1 $\mathrm{MtCO}_{2} \mathrm{e}$ abatement target in a model with endogenous or exogenous crop prices and average substitution elasticities

\begin{tabular}{|c|c|c|c|c|c|c|c|}
\hline \multirow{3}{*}{ Prices } & \multirow{3}{*}{$\begin{array}{l}\text { First-best } \\
\text { policy }\end{array}$} & \multicolumn{4}{|c|}{ Second-best policies } & & \\
\hline & & \multicolumn{2}{|c|}{$\begin{array}{c}\text { Spatially aggregated } \\
\text { emission factors }\end{array}$} & \multicolumn{2}{|c|}{$\begin{array}{l}\text { Regulation of } \\
\text { a single GHG }\end{array}$} & \multicolumn{2}{|c|}{$\begin{array}{l}\text { Regulation } \\
\text { of inputs }\end{array}$} \\
\hline & & Valley & $\mathrm{CA}$ & $\mathrm{CO}_{2}$ & $\mathrm{~N}_{2} \mathrm{O}$ & Tillage & Tillage \& N \\
\hline exog. & 0.42 & 0.44 & 0.45 & 0.57 & 0.52 & 1.04 & 0.86 \\
\hline endog. & 0.45 & 0.49 & 0.50 & 0.63 & 0.55 & 1.20 & 1.04 \\
\hline
\end{tabular}

Note: Values are expressed as a percentage of baseline economic welfare.

reductions in emission rates at a marginal cost of $\$ 20 / \mathrm{tCO}_{2} \mathrm{e}$ are observed for processing tomatoes and sunflower.

Table E.1 Crop average gross revenue in $\$ /$ ha and net emission rates in $\mathrm{tCO}_{2} \mathrm{e} / \mathrm{ha}$ in the SV and the SJV, weighted by crop acreages. Emission rates are indicated for the baseline $\left(e_{\$ 0}\right)$ and at the marginal cost of $\$ 20 / \mathrm{tCO}_{2} \mathrm{e}\left(e_{\$ 20}\right)$

\begin{tabular}{lcccccccc}
\hline & \multicolumn{3}{c}{ Sacramento Valley } & & \multicolumn{3}{c}{ San Joaquin Valley } \\
\cline { 2 - 3 } Crop & $\begin{array}{c}\text { Gross } \\
\text { revenue }\end{array}$ & $e_{\$ 0}$ & $e_{\$ 20}$ & & $\begin{array}{c}\text { Gross } \\
\text { revenue }\end{array}$ & $e_{\$ 0}$ & $e_{\$ 20}$ \\
\hline Alfalfa & 1863 & 1.39 & 1.35 & & 2514 & -0.30 & -0.35 \\
Corn & 1782 & 2.87 & 2.38 & & 1583 & 1.42 & 1.19 \\
Cotton & 3211 & 3.81 & 3.68 & & 3047 & 4.99 & 4.22 \\
Wheat & 734 & -0.15 & -0.36 & & 928 & -0.34 & -0.36 \\
Sunflower & 1637 & 5.66 & 4.11 & & 1471 & 4.28 & 3.35 \\
Processing tomatoes & 4265 & 6.17 & 3.92 & & 4571 & 6.22 & 4.63 \\
Safflower & 573 & 1.04 & 0.05 & & 1122 & 0.04 & -0.36 \\
\hline Average & 1951 & 2.62 & 1.75 & & 2312 & 2.63 & 1.91 \\
\hline
\end{tabular}

\section{E.2 Adjustments along the intensive margin}

In order to understand in more detail the contribution of adjustments along the intensive margin at higher abatement levels, in Table E.2 we report changes in input and tillage intensities and yields at a marginal social cost of $\$ 20 / \mathrm{tCO}_{2}$ e for the SV and the SJV. In the baseline, irrigation intensities tend to be higher in the 
Table E.2 Baseline average yields and production practices and percentage changes at a marginal social cost of $\$ 20 / \mathrm{tCO}_{2} \mathrm{e}$ in the SV and the SJV

\begin{tabular}{|c|c|c|c|c|c|c|c|c|c|}
\hline \multirow{2}{*}{\multicolumn{2}{|c|}{ Crop }} & \multicolumn{2}{|c|}{$\begin{array}{c}\text { Yield } \\
\text { (t/ha) }\end{array}$} & \multicolumn{2}{|c|}{$\begin{array}{l}\text { Water intensity } \\
\qquad(\mathrm{cm})\end{array}$} & \multicolumn{2}{|c|}{$\begin{array}{c}\text { N intensity } \\
(\mathrm{kg} / \mathrm{ha})\end{array}$} & \multicolumn{2}{|c|}{$\begin{array}{l}\text { Tillage } \\
\text { index }\end{array}$} \\
\hline & & $\overline{q_{i}} / \bar{x}_{i 1}$ & $\%$ & $\bar{x}_{i 2} / \bar{x}_{i 1}$ & $\%$ & $\bar{x}_{i 3} / \bar{x}_{i 1}$ & $\%$ & $\bar{T}_{i}$ & $\%$ \\
\hline$\Rightarrow$ & Alfalfa & 14.8 & 0 & 119 & 4 & 12 & - & 0.91 & - \\
\hline$\frac{0}{\sigma}$ & Corn & 66.8 & 2 & 116 & 3 & 189 & -3 & 0.91 & -14 \\
\hline$p$ & Cotton & 1.4 & 17 & 81 & 15 & 154 & 12 & 0.91 & -16 \\
\hline$\stackrel{0}{\stackrel{0}{二}}$ & Wheat & 5.3 & -12 & 16 & -8 & 141 & -28 & 0.91 & -17 \\
\hline$\stackrel{\Xi}{g}$ & Sunflower & 1.0 & 12 & 80 & 5 & 105 & -23 & 0.91 & -27 \\
\hline త్రై & Proc. tom. & 81.0 & 4 & 114 & 1 & 217 & -4 & 0.91 & -33 \\
\hline$\tilde{\pi}$ & Safflower & 2.4 & 17 & 8 & 25 & 111 & -11 & 0.91 & -26 \\
\hline $\overrightarrow{0}$ & Alfalfa & 17.9 & -5 & 127 & 0 & 9 & - & 0.91 & - \\
\hline శี & Corn & 57.7 & -1 & 123 & 3 & 228 & -3 & 0.91 & -8 \\
\hline$P$ & Cotton & 1.3 & 6 & 79 & 3 & 202 & -5 & 0.91 & -21 \\
\hline$\exists$ & Wheat & 5.7 & -10 & 52 & -3 & 247 & -6 & 0.91 & -5 \\
\hline 疋 & Sunflower & 0.9 & 7 & 79 & 2 & 105 & -22 & 0.91 & -20 \\
\hline 2 & Proc. tom. & 84.0 & 5 & 111 & 4 & 218 & -2 & 0.91 & -22 \\
\hline$\tilde{\tilde{D}}$ & Safflower & 4.1 & 9 & 65 & 21 & 123 & 12 & 0.91 & -15 \\
\hline
\end{tabular}

Note: We ignore the $\mathrm{N}$ fertilizer and tillage responses for alfalfa, a $\mathrm{N}$-fixing perennial crop. Total changes in water and $\mathrm{N}$ fertilizer use at the Central Valley level are $0 \%$ and $-10 \%$, respectively.

SJV, characterized by a drier climate, than in the SV. N and tillage intensities fall for most crops in the two valleys because these intensities are positively correlated with GHG emissions (see Figure B.1). The largest reductions in N intensity are observed for wheat and sunflower, which can be explained by the combination of a very low yield elasticity with respect to $\mathrm{N}$ fertilizer and the positive correlation between $\mathrm{N}$ intensity and GHG emissions. The most dramatic changes in tillage are observed for processing tomatoes and sunflower. In general, crops whose acreage expands such as wheat and alfalfa experience average yield reductions because of reduced water and $\mathrm{N}$ intensities and the decreasing returns to scale imposed by the model specification. In contrast, crops whose acreage contracts substantially such as cotton and sunflower experience sizable average yield increases, despite 
occasionally large reductions in $\mathrm{N}$ intensity. ${ }^{39}$

${ }^{39}$ Our model does not constrain fertilizer or irrigation intensities to remain above a lower bound. 